\title{
Pathomechanisms and therapeutic opportunities in radiation-induced heart disease: from bench to bedside
}

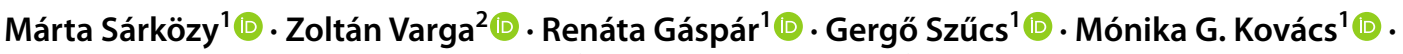

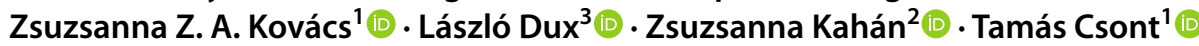

Received: 29 October 2020 / Accepted: 16 January 2021 / Published online: 16 February 2021

(c) The Author(s) 2021

\begin{abstract}
Cancer management has undergone significant improvements, which led to increased long-term survival rates among cancer patients. Radiotherapy (RT) has an important role in the treatment of thoracic tumors, including breast, lung, and esophageal cancer, or Hodgkin's lymphoma. RT aims to kill tumor cells; however, it may have deleterious side effects on the surrounding normal tissues. The syndrome of unwanted cardiovascular adverse effects of thoracic RT is termed radiation-induced heart disease (RIHD), and the risk of developing RIHD is a critical concern in current oncology practice. Premature ischemic heart disease, cardiomyopathy, heart failure, valve abnormalities, and electrical conduct defects are common forms of RIHD. The underlying mechanisms of RIHD are still not entirely clear, and specific therapeutic interventions are missing. In this review, we focus on the molecular pathomechanisms of acute and chronic RIHD and propose preventive measures and possible pharmacological strategies to minimize the burden of RIHD.
\end{abstract}

Keywords Onco-cardiology $\cdot$ Radiation heart sequelae $\cdot$ Molecular pathomechanisms of radiation-induced heart disease · Prevention and therapy of radiation-induced heart disease

\section{Introduction}

Cardiovascular and cancerous diseases are the leading causes of mortality worldwide $[1,2]$. The most common cancerous diseases are thoracic malignancies, including lung and breast cancers among adults [2]. Recently, cancer management has

Zsuzsanna Kahán and Tamás Csont authors contributed equally to the manuscript.

Márta Sárközy

sarkozy.marta@med.u-szeged.hu

$\checkmark$ Zsuzsanna Kahán

kahan.zsuzsanna@med.u-szeged.hu

Tamás Csont

csont.tamas@med.u-szeged.hu

Zoltán Varga

varga.zoltan@med.u-szeged.hu

Renáta Gáspár

gaspar.renata@med.u-szeged.hu

Gergő Szúcs

szucs.gergo@med.u-szeged.hu

Mónika G. Kovács

kovacs.monika.gabriella@med.u-szeged.hu undergone significant improvement, leading to increased longterm survival rates among cancer survivors. Consequently, age-related chronic diseases and cardiovascular risk factors, including hypertension, diabetes mellitus, hyperlipidemia, chronic kidney disease, and smoking, are often aggravated by chronic side effects of multimodality cancer therapy, accelerating the progression of atherosclerosis and increasing the burden of cardiovascular diseases (CVDs) in cancer survivors [3].

Zsuzsanna Z. A. Kovács

kovacs.zsuzsanna@med.u-szeged.hu

László Dux

dux.laszlo@med.u-szeged.hu

1 MEDICS Research Group, Department of Biochemistry, Interdisciplinary Center of Excellence, University of Szeged, Szeged 6720, Hungary

2 Department of Oncotherapy, Faculty of Medicine, University of Szeged, Szeged 6720, Hungary

3 Department of Biochemistry, Faculty of Medicine, University of Szeged, Szeged H-6720, Hungary 
While high-energy ionizing radiation successfully destroys cancer cells, at the same time, it may have harmful effects on the surrounding healthy tissues leading to various side effects [4]. RT has been frequently used in thoracic malignancies, including breast, lung, esophageal cancer, thymoma, and Hodgkin's lymphoma, which could be in close anatomical proximity to the heart [5]. Depending on the RT technique and dose, the heart may be at risk of being exposed to ionizing radiation resulting in radiogenic sequelae in a dose-dependent manner [6]. The syndrome of unwanted cardiovascular side effects of thoracic RT is called radiation-induced heart disease (RIHD), and the risk of development of RIHD is a critical concern in current oncology practice. RIHD includes structural and functional abnormalities of the pericardium, coronary vessels, myocardium, valves, and conduction system [7, 8]. Much of our current knowledge on radiation-induced cardiovascular complications in cancer survivors is based on the patients' data coming from the era of the 1980s or before that, with less developed RT techniques, extended RT fields, and high radiation doses $[4,9]$. The earliest data indicating the presence of RIHD originate from follow-up studies of lymphoma and breast cancer patients due to the high incidence and high cure rate of these diseases $[10,11]$. In clinical practice, the consequences of RIHD mostly emerge in breast cancer patients receiving left-sided postoperative RT and less frequently in esophageal cancer patients treated with preoperative chemo-radiotherapy [6].

The prevention or management of radiogenic CVDs has become a challenge in clinical practice since RIHD can worsen the outcome, quality of life, and health care costs in long-term cancer survivors $[12,13]$. These factors have recently contributed to the emergence of a new specialty termed onco-cardiology or cardio-oncology. Unfortunately, therapeutic options for RIHD are currently insufficient. Therefore, understanding the exact molecular mechanisms in the progression of RIHD is necessary for developing preventive and therapeutic strategies without attenuating the effect of RT on cancer cells. Tailored surveillance of patients according to their risk status serves early intervention if necessary $[12,13]$.

In this review, we summarize our current knowledge on the molecular pathomechanisms of the development and progression of RIHD and overview those potential pharmacological and other strategies that may be suitable for the prevention or management of RIHD.

\section{Clinical manifestations of RIHD}

RIHD may manifest in a broad spectrum of cardiovascular complications, including acute and chronic pericarditis, ischemic heart disease (IHD), cardiomyopathy and heart failure (HF), valvular heart disease, and cardiac conduction abnormalities [4, 14] (Fig. 1). Complications typically appear years to decades after the irradiation, showing a median of 10-15 years. The overall absolute risk of cardiac death is related to the mean heart dose (MHD) of RT [9, 15]. Radiation-induced cardiovascular complications are more severe with (i) higher total radiation dose [6], (ii) extended target volume exposure with closer tumor localization to the heart [16], (iii) younger age at the radiation exposure [9, 15], (iv) longer follow-up duration [17], (v) concomitant therapy with cardiotoxic chemotherapeutic drugs such as anthracyclines and biological agents [18, 19], (vi) presence of genetic factors, and (vii) comorbidities and cardiovascular risk factors [3].

\section{Acute forms of RIHD}

\section{Acute pericarditis}

Acute pericarditis could be the earliest form of RIHD [20] (Fig. 1). Before the era of selective RT-techniques in the late 1980 s, $80 \%$ of patients receiving thoracic irradiation suffered from acute pericarditis [20]. In these cases, high MHD (>36 Gy) administered to $>30 \%$ of the heart was responsible for the development of acute exudative pericarditis $[5,20]$. Nowadays, its occurrence is rare $(<5 \%)$ due to alertness and the modern heart-sparing RT-techniques [13, 21]. Acute pericarditis causes chest pain, fever, and ECG abnormalities. Approximately half of the affected patients suffer from hemodynamic abnormalities due to significant pericardial effusion. Even cardiac tamponade can develop necessitating intervention [20].

\section{Acute conduction system abnormalities}

In the acute phase, some patients develop mostly reversible asymptomatic ECG repolarization abnormalities, which rarely persists (the incidence is unknown due to the lack of screening during or shortly after RT) [14]. These events may occur in response to transitory circulatory/metabolic changes, or if irradiation induces the development of definitive structural changes in the conduction system (e.g., via increasing oxidative/nitrosative/nitrative stress or inflammation), that probably affects an irrelevant part of the heart only.

\section{Chronic forms of RIHD}

\section{Chronic pericarditis}

The presence of pericardial effusion in the acute phase might predispose patients to chronic pericarditis of delayed onset from months to years [14] (Fig. 1). Certain chemotherapeutic 


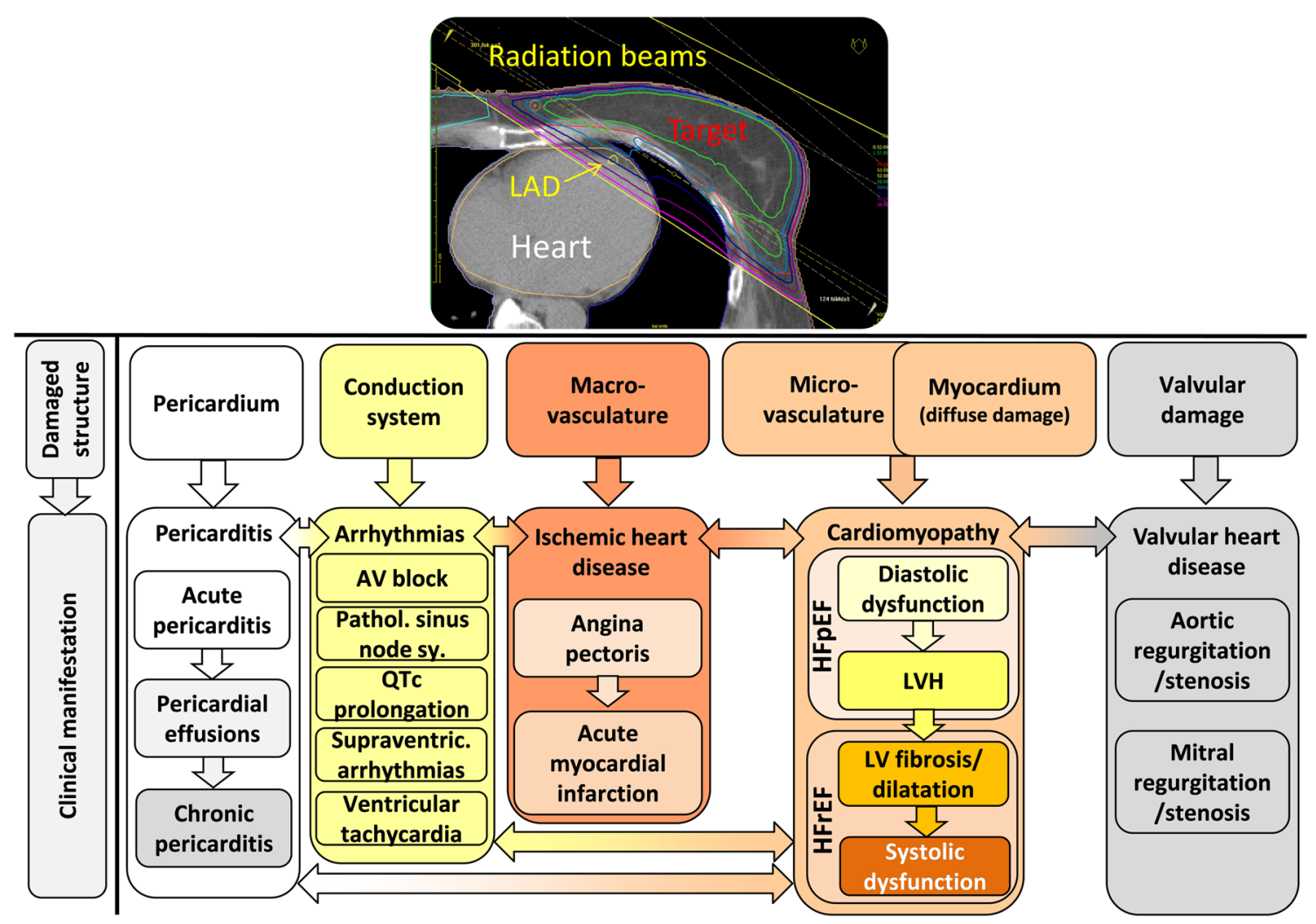

Fig. 1 Possible clinical manifestations of RIHD. RIHD is a progressive disease that covers a broad spectrum of cardiac pathology. RIHD may manifest as acute or chronic pericarditis, conduction system abnormalities, ischemic heart disease, cardiomyopathy, heart failure

drugs (e.g., anthracyclines, cyclophosphamide, and bleomycin) may enhance the risk of radiogenic pericarditis development [20]. Up to $20 \%$ of patients develop chronic constrictive pericarditis with severe symptoms requiring pericardiectomy at a median time of 11 years post-irradiation [22].

\section{Ischemic heart disease (IHD)}

Our understanding concerning the burden of radiogenic IHD is based the most on epidemiological studies $[6,8,9$, $11,15]$. Nevertheless, estimations may be given using normal tissue complication probability models [23]. However, prospectively collected data with careful follow-up observations are needed [24]. In the various studies, different end-points, dose parameters, and statistical methods were used (Table 1). The studied populations also differed: some included all irradiated patients $[8,9,11,15]$ while others, only patients with major IHD events such as the need for coronary intervention/acute myocardial infarction (AMI) or IHD-related death $[25,26]$. The risk of coronary artery disease (CAD) is clearly radiation dose-dependent. The traditional reference dose parameter is MHD $[8,9]$. Nevertheless, including $\mathrm{HFpEF}$ and $\mathrm{HFrEF}$, or valvular heart disease, according to the site of damage. $L A D$ left descending coronary artery, $L V H$ left ventricular hypertrophy, $H F p E F$ heart failure with preserved ejection fraction, $H F r E F$ heart failure with reduced ejection fraction

Bogaard et al. showed that among other dose parameters, the volume of the left ventricle receiving at least 5 Gy (LVV5) is the most sensitive predictor of coronary events [27]. Most studies agree that beyond radiation dose, risk factors for CAD or the history of IHD, and young age are also determinants of outcome (Table 1) [8, 9, 11, 15, 27].

Breast cancer patients receiving radiation doses of $<2 \mathrm{~Gy}$, 2-4 Gy, 5-9 Gy, and $>10$ Gy had a dose-dependent excess risk for angina pectoris, AMI, and sudden cardiac death of $10 \%, 30 \%, 40 \%$, and $116 \%$, respectively $[8,9,27]$ (Table 1 ; Fig. 1). The risk for IHD increased linearly with the MHD by 7.4\% per $1 \mathrm{~Gy}$ absorbed dose with no apparent lower threshold [8]. Similar dose-response results were found by Jacobse et al. in a nested case-control study: every 1 Gy increase in MHD was associated with a $6.4 \%$ increase in the risk of AMI; in MHD > 20 Gy cases, the risk of AMI was 3.4 times higher (Table 1) [15]. Based on modern three-dimensional conformal radiation therapy (3DCRT) dose-volume data, Bogaard et al. also confirmed these results. They introduced the LV-V5 parameter indicating a $1.7 \%$ increase in coronary events incidence by every $5 \mathrm{~Gy}$ increase of dose to the left ventricle [27]. Among lymphoma patients, identical results were found on MHD data and long-term AMI incidence as 


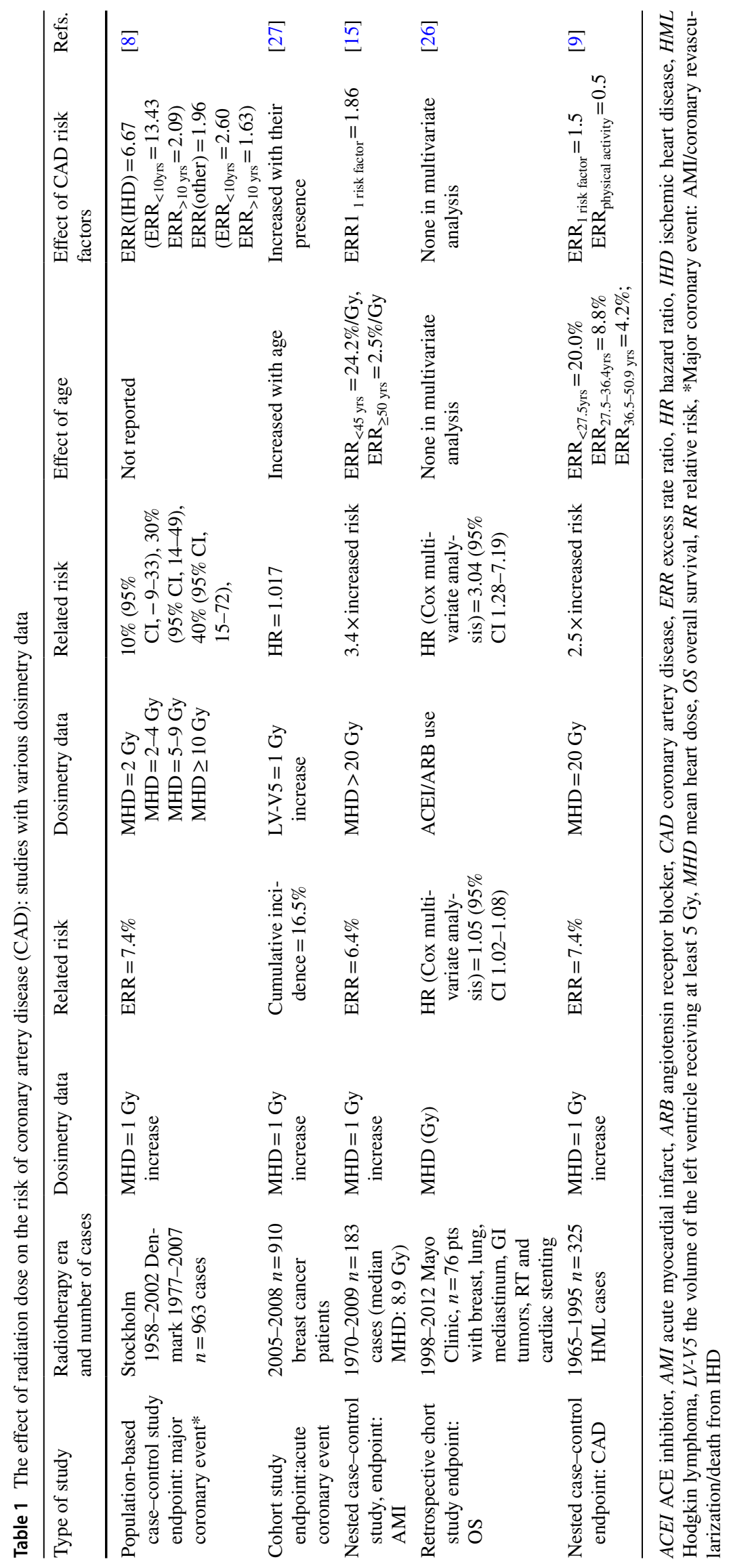


in the classic Darby-study; in MHD > 20 Gy cases, 2.5 times higher AMI risk was detected [9]. The dose-dependent and irradiated volume-dependent nature of RIHD-related survival were demonstrated in a retrospective cohort study in lymphoma patients with CAD requiring coronary intervention [26]. The strongest predictor of a major coronary event is left-sided RT [28, 29]. Boekel et al. showed a significantly increased risk of IHD when the chest wall or the internal mammary nodes were irradiated independent of laterality in breast cancer patients [16]. The association between the radiation dose to a cardiac segment and the injury of the affected structure was demonstrated by Taylor et al. [30]. In this study, the highest RT doses were detected in the distal part of the left anterior descending (LAD) artery [30].

\section{Cardiomyopathy and heart failure (HF)}

Radiation-induced cardiomyopathy and consequent HF are progressive multifactorial diseases, which may evolve over several years (Fig. 1). They are often aggravated by medical anti-cancer therapies, concomitant radiation-induced valvular heart disease (VHD), or IHD. RT-induced cardiomyopathy and HF cover a spectrum of cardiac pathological conditions among which a typical initial phase is HF with preserved ejection fraction (HFpEF). HFpEF is characterized by diastolic dysfunction and compensatory left ventricular hypertrophy (LVH) (Fig. 1). [31-34]. Later on, progressive interstitial fibrosis develops, separating and replacing the cardiomyocytes, which ultimately results in HF with reduced ejection fraction (HFrEF) [20,35]. A tolerance dose of $40 \mathrm{~Gy}$ has been estimated for the human myocardium for the end-point of diffuse myocardial injury [20]. Indeed, diffuse myocardial injury is more common in patients who have received higher RT doses (> $60 \mathrm{~Gy}$ ) and/or anthracycline chemotherapy [14, 29]. Radiation-induced cardiomyopathy is often asymptomatic. Its risk increases 5 years after RT but may develop even decades after RT [20].

\section{Valvular heart disease (VHD)}

Within the first 10 years after RT, the earliest morphological changes appear to be leaflet thickening, fibrosis, shortening and calcification, and consequent regurgitation preferentially at the mitral or aortic valves [20] (Fig. 1). The progression to fibrotic thickening and calcification of the valves may lead to stenosis, which develops mainly in the aortic valve approximately 20 years after RT [20]. The rate of VHD correlates better with the RT dose to the affected [36] valve than to the mediastinal dose [37]. Myocardial ischemia and hypoxia caused by IHD and fibrosis also play a role in the development of VHD that may contribute to HF [14].

\section{Chronic conduction system abnormalities}

In the chronic phase after irradiation, in about $5 \%$ of the cases, radiogenic conduction system abnormalities develop $[37,38]$. Among these, bundle branch blocks and firstdegree atrioventricular (AV) block occur most commonly [39], but pathological sinus node syndrome, QTc prolongation, supraventricular arrhythmias, and ventricular extrasystole or tachycardia may also develop [14, 39, 40] (Fig. 1). Circulatory changes such as autonomic dysfunction with tachycardia and blunted blood pressure, rarely syncope or even sudden death related to the denervation-like status of the heart may occur; (nevertheless, similar symptoms due to neck irradiation with injury of the vessels and baroreceptors should be distinguished) [38, 41, 42].

Late conduction anomalies may be explained with various pathomechanisms. Most obviously, fibrotic lesions resulted from decreased microvessel density, chronic hypoxia, compensatory hypertrophy are behind the abnormalities [35, 43-46]. In other cases, RT-related valvular disease and increased right atrial pressure cause atrial arrhythmias [38], or exercise-induced ischemia of the atrioventricular node due to the stenosis of the right coronary artery results in $\mathrm{AV}$ block [40, 47].

\section{Pathomechanisms of RIHD}

RIHD is a progressive multifactorial disease that has overlapping common and different molecular pathways in the acute and chronic phases. RT simultaneously causes damage to the macrovasculature (i.e., coronary arteries), the microvasculature, and the myocardium (i.e., diffuse injury) [7]. Key questions relating to the precise molecular mechanisms of the disease progression in RIHD from acute to chronic heart diseases remained unanswered. The chain of biological events from acute to chronic forms is more likely a complex interaction between molecular processes. A substantial body of evidence suggests that the radiation-induced immediate oxidative/nitrosative/nitrative damage of macromolecules, including DNA, proteins, and lipids, is the initiating event in RIHD. At this early phase, the increased oxidative/nitrative/nitrosative stress triggers other biological processes, including endothelial cell injury, acute inflammation, and the various forms of cell death $[35,43,44]$ (Fig. 2). In the early chronic phase of RIHD, several compensatory mechanisms, including endothelial cell proliferation and cardiac hypertrophy, develop in the sublethally damaged surviving cells [35, 43, 44] (Fig. 3). If these compensatory mechanisms are exhausted, chronic inflammatory processes, fibrosis, and endothelial senescence play the central role in the disease progression [35, 43, 44] (Fig. 3). The exact molecular 


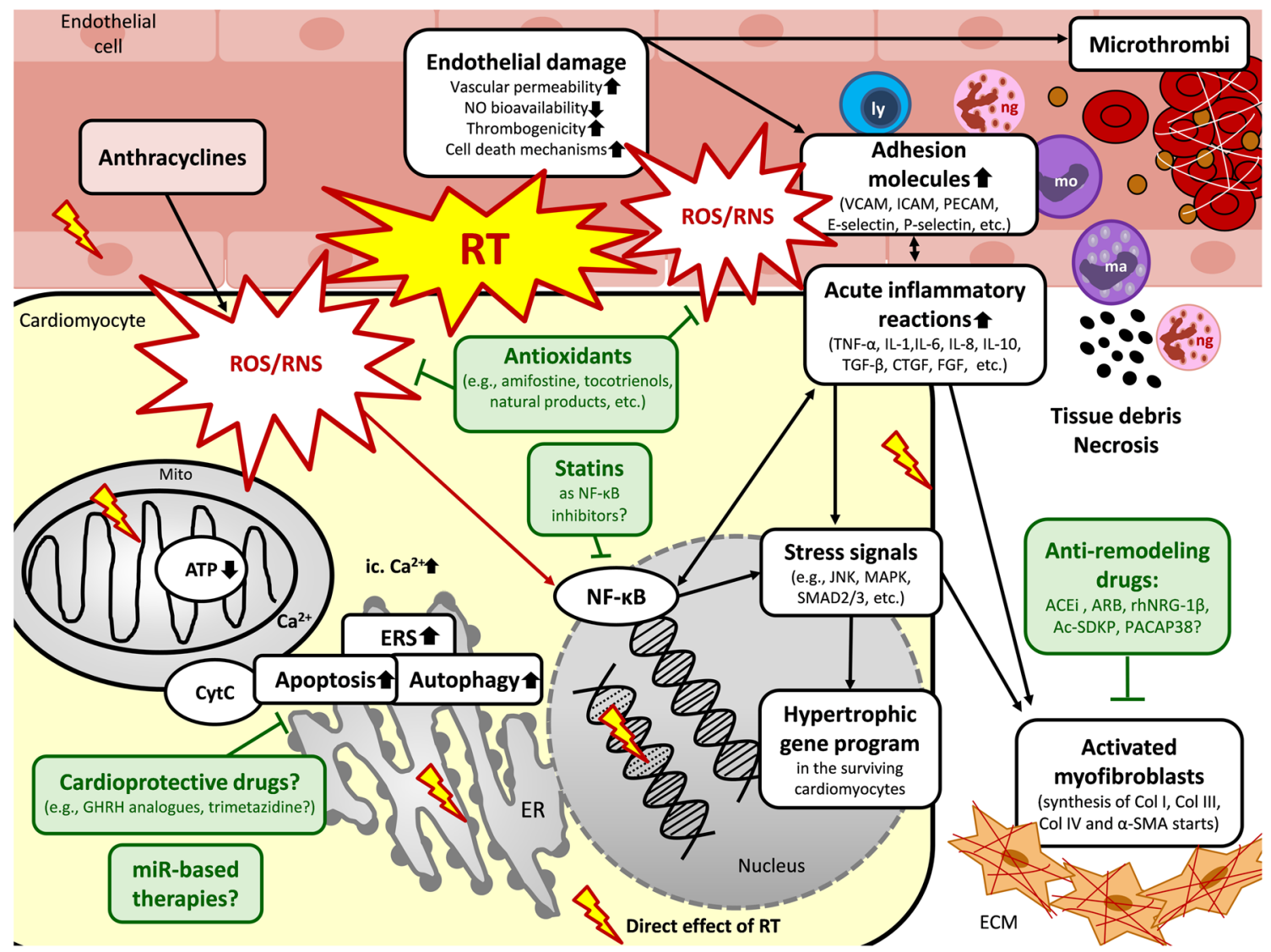

Fig. 2 Putative mechanisms in the acute phase of RIHD and potential pharmacological interventions. RT could induce immediate oxidative/nitrosative/nitrative damage of macromolecules, including DNA, proteins, and lipids, in all cardiac cell types. The increased oxidative/ nitrative/nitrosative stress triggers other biological processes, including acute inflammation, and cell death forms in the acute phase of RIHD in the different cell types. Parallel, hypertrophic, and fibrotic gene programs start in the surviving cardiomyocytes as compensatory mechanisms. Potential preventive and therapeutic pharmacologic agents are depicted in green boxes targeting different molecular mechanisms. ACE $i$ angiotensin-converting enzyme inhibitors, Ac$S D K P \mathrm{~N}$-acetyl-Ser-Asp-Lys-Pro, $A R B$ angiotensin receptor blockers, $\alpha$-SMA $\alpha$-smooth muscle actin, ATP adenosine triphosphate,
$\mathrm{Ca}^{2+}$ calcium ion, $\mathrm{Col}$ collagen, CTGF connective tissue growth factor, $C y t C$ cytochrome C, ERS endoplasmic reticulum stress, $F G F$ fibroblast growth factor, $G H R H$ growth hormone-releasing hormone, $I C A M$ intercellular adhesion molecules, $I L$ interleukin, JNK c-Jun $\mathrm{N}$-terminal kinases, ly lymphocyte, $m a$ macrophage, MAPK mitogenactivated protein kinase, $m i R$ microRNA, mo monocyte, Mito mitochondrion, $N F-\kappa B$ nuclear factor- $\kappa \mathrm{B}, n g$ neutrophil granulocyte, $N O$ nitric oxide, $P A C A P 38$ pituitary adenylate cyclase-activating polypeptide 38, PARPIpoly-ADP-ribose-polymerase 1, PECAM platelet endothelial cell adhesion molecule, $r h N R G-1 \beta$ recombinant human neuregulin-1 $\beta, R O S / R N S$ reactive oxygen and nitrogen species, $R T$ radiotherapy, $T G F-\beta$ tissue growth factor- $\beta, T N F-\alpha$ tumor necrosis factor- $\alpha, V C A M$ vascular cell adhesion molecule transition mechanisms and time points between the acute to compensated or decompensated chronic forms of RIHD are yet unknown. Moreover, several pathomechanisms, including oxidative/nitrative/nitrosative stress, cell death, and inflammatory processes, overlap during the acute and chronic phases of RIHD. These mechanisms could activate and potentiate each other leading to a vicious cycle in the RIHD progression. Therefore, the precise understanding of the complex interplay of these acute and chronic molecular mechanisms would help to develop strategies to counteract the progression of RIHD. In this section, we briefly summarize the predominating pathomechanisms in which have a role in developing the acute and chronic forms of RIHD.

\section{Pathomechanisms in the acute phase of RIHD}

\section{Mechanisms of increased oxidative/nitrosative/nitrative stress in the acute phase of RIHD}

Increased oxidative/nitrosative/nitrative stress plays a crucial role in developing both the desired anticancerous effects and the undesired side effects of RT. Absorption of ionizing radiation used for RT may induce both direct and indirect effects in all cell types [48] (Fig. 2). Ionizing radiation can directly disrupt atomic structures, leading to further chemical and biological changes [49] (Fig. 2). Approximately 80\% of the cells is water. Therefore, the initial radiation-induced 
cellular damage is mostly caused by the direct radiolysis of water generating reactive species leading to indirect effects [48]. The major reactive species produced in the radiolysis of water are superoxide $\left(\mathrm{O}_{2}{ }^{--}\right)$, hydroxyl radical $\left({ }^{\bullet} \mathrm{OH}\right)$, electrons $\left(\mathrm{e}^{-}\right)$, and hydrogen peroxide $\left(\mathrm{H}_{2} \mathrm{O}_{2}\right)$. Organic radicals $\left(\mathrm{R}^{\bullet}\right)$ are also formed by $\mathrm{H}$-abstraction reactions initiated by - OH radicals. These carbon-centered radicals usually react rapidly with $\mathrm{O}_{2}$ to give peroxyl radicals $\left(\mathrm{RO}_{2}{ }^{\bullet}\right)$, which are stronger oxidizing agents than their parent radicals. The $\mathrm{RO}_{2}$ radicals can abstract $\mathrm{H}^{\bullet}$ from other molecules to form hydroperoxides $(\mathrm{ROOH})$ [48]. Ionizing radiation-induced tissue injury may up-regulate inducible nitric oxide synthase (iNOS), thereby generating a large amount of nitric oxide $\left({ }^{\bullet} \mathrm{NO}\right)$, which can react with $\mathrm{O}_{2}{ }^{--}$to form peroxynitrite $\left(\mathrm{ONOO}^{-}\right)$and secondarily other reactive nitrogen species (RNS) [48-50] (Fig. 2). Other enzymatic sources for reactive oxygen species (ROS) include NADPH oxidases (NOX isoforms), lipoxygenases (LOX), cyclooxygenases (COX), peroxidases in inflammatory cells, and xanthine oxidase, which can be activated by RT-induced tissue injury $[35,48]$. Ionizing radiation may also disrupt the mitochondrial respiratory chain contributing to persistent oxidative/ nitrosative/nitrative stress. The removal of ROS/RNS during RT via the key antioxidant enzymatic systems, including, e.g., superoxide dismutase (SOD), catalase, glutathione peroxidase, glutathione reductase, and heme oxygenase, may also be insufficient [48]. Accumulated ROS/RNS during and shortly after irradiation may cause macromolecular damage including, lipid peroxidation, protein oxidation/ nitration, inactivation of enzymes, DNA damage, interaction with both DNA repair enzymes (e.g., poly-ADP-ribose polymerase 1 [PARP1], p53) and transcription factors (e.g.,

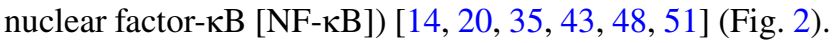
Oxidative/nitrative stress can also induce acute inflammation and cell death via different mechanisms. The macromolecular and cellular damage may result in the activation of the inflammatory response (interleukins [IL] including, e.g., IL-1, IL-6, IL-8, IL-10, tumor necrosis factor-alpha $[\mathrm{TNF}-\alpha]$, and transforming growth factor-beta [TGF- $\beta]$ ), stress signals (e.g., c-Jun N-terminal kinase [JNK], and p38MAPK) or cell death (e.g., apoptosis and necrosis), and dysregulation of autophagy. The oxidation/nitration of proteins involved in excitation-contraction coupling, contractility, $\mathrm{Ca}^{2+}$-handling, elements of the mitochondrial electron transport chain and Krebs cycle, metabolism, and extracellular matrix might result in acute and chronic deleterious events [14, 20, 35, 43, 48, 51] (Fig. 2).

\section{Endothelial cell injury and acute inflammation in RIHD}

Endothelial cell injury is considered the primary cause of radiation damage in cardiac tissue [14, 35] (Fig. 2). Within minutes after RT, increased vascular permeability and vasodilation are present $[5,35,43]$. In the first few hours and days after RT, activated NF-kB [52, 53] may induce the secretion of adhesion molecules including, e.g., E-selectin [54], P-selectin [54], intercellular adhesion molecule-1 (ICAM-1) [54], vascular cell adhesion molecule-1 (VCAM-1) [55], platelet endothelial cell adhesion molecule-1 (PECAM-1) [55], and cytokines (e.g., IL-6, IL-8) $[56,57]$ in the damaged endothelial cells thereby activating leukocyte rolling, arrest, and transmigration [35, 43, 52]. The predominant inflammatory cells in the acute phase are neutrophil granulocytes. They infiltrate the endocardium, myocardium, and epicardium of the irradiated heart. They are the first responders releasing pro-inflammatory cytokines (e.g., monocyte chemotactic protein [MCP], TNF$\alpha$, and IL-8) to recruit other inflammatory cells $[5,43,59]$ (Fig. 2). Recruited inflammatory cells may release further pro-inflammatory (e.g., IL-1, and IL-6) and pro-fibrotic cytokines including, e.g., TGF- $\beta$, connective tissue growth factor (CTGF), platelet-derived growth factor (PDGF), and fibroblast growth factor (FGF) [43, 58, 60-62]. Additionally, adhesion molecules, inflammatory and pro-fibrotic cytokines (e.g., ICAM-1, IL-6, and FGF) can also be produced by the microvascular endothelial cells suggesting their role in the maintenance of the pro-inflammatory state [35, 63-65]. Matrix metalloproteinases (MMPs), including MMP-1 and MMP-2, could immediately be activated by RT in endothelial cells, possibly via the increased oxidative/nitrosative/ nitrative stress or inflammatory mechanisms [43, 58, 66, 67]. These proteases may degrade the endothelial basement membrane, allowing effective recruitment of neutrophils and macrophages to cellular injury sites in order to phagocyte tissue debris [43, 68] (Fig. 2). The recruited inflammatory cells and the damaged endothelial cells can produce a large amount of $\mathrm{O}_{2}{ }^{--}$and ${ }^{\bullet} \mathrm{NO}$, the latter via iNOS, which results in further $\mathrm{ONOO}^{-}$formation $[58,69]$. The decreased bioavailability of ${ }^{\bullet} \mathrm{NO}$ could lead to endothelial damage, vascular dysfunction, vasoconstriction, and tissue hypoxia [35]. The mechanisms described above may lead to focal endothelial denudation and endothelial dysfunction, triggering initial arteriosclerotic lesions in larger coronary arteries [35].

\section{Increased thrombogenicity and acute inflammation in RIHD}

Initial endothelial damage in the microvasculature could also activate the coagulation cascade leading to fibrin deposition [43] (Fig. 2). Notably, it can be a result of (i) RT-induced endothelial damage itself [20], (ii) the thrombomodulin inhibition caused by TGF- $\beta$ [70], and (iii) increased release of von Willebrand factor (vWF) from endothelial cells [35]. Several coagulation factors (e.g., thrombin) may induce the endothelial release of IL- 8 and MCP, promoting the expression of adhesion molecules and chemotaxis of neutrophil granulocytes [71]. RT can also activate COX and LOX 
enzymes, which produce bioactive eicosanoids from arachidonic acid, including, e.g., prostaglandins, prostacyclin, thromboxanes, and leukotrienes in different cell types [72]. These bioactive molecules are well-known mediators of inflammation via vasodilation or vasoconstriction, vascular permeability, extravasation of leukocytes, and microthrombus formation [72]. Decreased bioavailability of ${ }^{\bullet} \mathrm{NO}$ can lead to vasoconstriction, aggravating thrombogenicity [35].

\section{Endoplasmic reticulum stress and apoptosis in RIHD}

Irradiation can induce endoplasmic reticulum stress (ERS) and cell death in the different cell types of cardiac tissue, including cardiomyocytes, endothelial cells, fibroblasts, and cells of the conducting system [35] (Fig. 2). RT-induced irreversible damage in the structure of cellular compartments and molecules, mitochondrial dysfunction, and ERS are the critical components in cell death pathways in RIHD [14]. During ERS, the ER is overwhelmed with incorrectly folded or unfolded proteins [73]. The protein overload induces disruption of protein homeostasis and activates the unfolded protein response (UPR). The UPR leads to apoptotic cell death via three major pathways [73]. These are (i) the protein kinase R-like endoplasmic reticulum kinase (PERK)regulated, (ii) the activating transcription factor 6 (ATF6), and (iii) the inositol-requiring enzyme 1 (IRE1) pathways [74]. PERK inhibits protein translation via phosphorylation and subsequent inactivation of the eukaryotic translation initiator factor $2 \alpha$ (eIF2- $\alpha$ ) to avoid further misfolded protein accumulation. The ATF6 and IRE1 pathways activate transcription of genes involved in ER-associated protein degradation, protein folding, and ER membrane expansion. IRE can also inhibit the anti-apoptotic activity of Bcl-2 and Bcl-XL [74]. After irradiation of cardiomyocytes, the stimulated ER releases calcium ions into the cytoplasm, leading to mitochondrial calcium overload, cytochrome-C release into the cytoplasm, and activation of the pro-apoptotic Bax [75, 76] (Fig. 2). The translocation of Bax from the cytoplasm to the mitochondrial outer membrane induces mitochondrial membrane permeability transition (MPT), leading to mitochondrial swelling, depolarization of the membrane, uncoupled electron transport, and oxidative phosphorylation [75] (Fig. 2).

\section{Necrosis in RIHD}

Several death initiators, signaling pathways, and effector molecules are common key mediators in both apoptosis and necrosis [77]. Triggered by elevated oxidative/nitrosative/ nitrative stress and calcium ion toxicity after RT, the MPT is a causative event in cell death mechanisms, including both apoptosis and necrosis in cardiomyocytes [14]. Extrinsic stimuli via cell surface death receptors, such as TNF- $\alpha$, Fas, and TNF-related apoptosis-inducing ligand (TRAIL) receptors, can also stimulate both types of cell death [77] (Fig. 2). Necrotic cells release factors like endogenous mitochondrial damage-associated molecular patterns (DAMPs), including high mobility group box 1 (HMGB1), ATP, and IL- $1 \alpha$ produced by stressed cells to evoke an inflammatory response $[78,79]$. These signals are sensed by the nucleotide-binding domain and leucine-rich-repeat-containing family pyrin 3 (NLRP3), a core protein of the inflammasome. NLRP3 activates and releases the pro-inflammatory cytokine IL-1 $\beta$ and IL-18. RT may activate NLRP3 inflammasome via multiple other mechanisms, including increased oxidative/nitrosative/ nitrative stress, calcium ion influx, and potassium ion efflux [78, 79]. NLRP3 inflammasome was suggested to play a critical role in the development of RIHD via its complex relationship with cell death and inflammatory processes [78, 79].

\section{Autophagy in RIHD}

Autophagy, a predominantly cytoprotective catabolic process, has been linked to apoptosis and necrosis, providing either a pro-survival or pro-death function [80]. The homeostatic role of autophagy is particularly critical in terminally differentiated cells, including cardiomyocytes. Cytosolic components or cell organelles are packed into double membraned autophagic vesicles that fuse with lysosomes. It results in the degradation and recycling of cellular components, thereby promoting survival [77]. However, the overactivation of autophagy could be harmful under pathological conditions. RT can directly or indirectly damage DNA, which activates repairing signaling pathways. Many proteins participating in DNA damage repairing signaling pathways, such as p53, ATM, PARP1, FOXO3a, mTOR, and SIRT1, are involved in the regulation of autophagy (Fig. 2). Irradiation may also damage extranuclear targets such as plasma membrane, mitochondria, and ER, leading to increased ceramide, ROS/RNS, and calcium ion concentrations, which can activate many autophagic pathways [81, 82].

\section{Pathomechanisms in the chronic phase of RIHD}

\section{Mechanisms of the increased oxidative/nitrosative/nitrative stress in the chronic phase of RIHD}

The early biochemical modifications, which occur during or shortly after the radiation exposure, were thought to be responsible for most of the effects of ionizing radiation in cells [48]. The initial oxidative/nitrative/nitrosative stress is caused by the radiolysis of water induced by ionizing radiation (see also Sect. "Mechanism of the increased oxidative/ nitrosative/nitrative stress in the chronic phase of RHID). However, oxidative and nitrative changes might continue to 
present months or years after the initial radiation exposure, presumably due to continuously increased generation of ROS/RNS via different mechanisms including, e.g., mitochondrial damage, inflammatory and cell death processes (see also Sect. "The interplay of oxidative /nitrosative/nitrative stress with chronic inflammatory pathway in RIHD".), overexpression of ROS-generating enzymes in cardiac tissue and insufficient antioxidant mechanisms [20, 48] (Fig. 3). Remarkably, these processes occur both in the irradiated cells and their progeny $[48,49]$. It is also well-known that aging, cardiovascular risk factors (e.g., hypertension, diabetes mellitus, hypercholesterolemia, and chronic kidney disease) [83-85], and concomitant anthracycline therapy [86] are also associated with increased oxidative/nitrosative/ nitrative stress and low-grade chronic inflammation (Fig. 3). These factors might further aggravate the progression of RIHD.

\section{The interplay of oxidative/nitrosative/nitrative stress with chronic inflammatory pathways in RIHD}

In the chronic phase of inflammation, the elevated ROS/ RNS levels may result in increased expression and activity of TGF- $\beta$ [58]. TGF- $\beta$ and other growth factors (e.g., CTGF

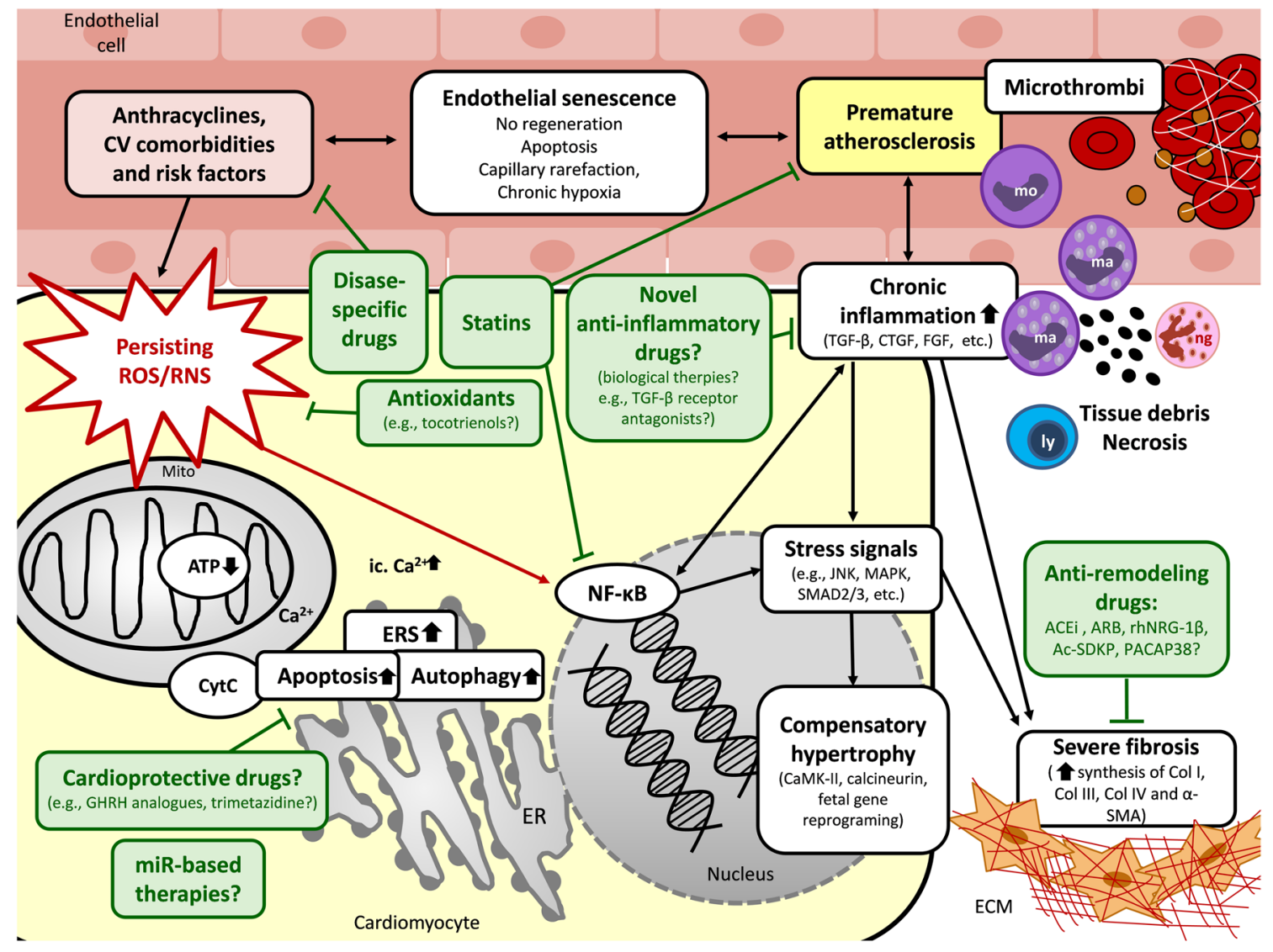

Fig. 3 Putative mechanisms in the chronic phase of RIHD and potential pharmacological interventions. Several pathomechanisms in the chronic phase of RIHD including oxidative/nitrative/nitrosative stress, cell death, and inflammatory processes, overlap during the acute and chronic phases of RIHD. These mechanisms could activate and potentiate each other in the different cardiac cell types leading to a vicious cycle. In the early chronic phase of RIHD, compensatory mechanisms including manifest left ventricular hypertrophy and endothelial cell proliferation are predominant. If these compensatory mechanisms are exhausted, fibrosis and endothelial senescence play the central role in the late phase of disease progression. The exact molecular transition points from acute to compensated and decompensated chronic forms of RIHD are unknown yet. Potential preventive and therapeutic pharmacologic agents are depicted in green boxes targeting different molecular mechanisms. ACEi angiotensin- converting enzyme inhibitors, $A R B$ angiotensin receptor blockers, $\alpha$-SMA $\alpha$-smooth muscle actin, ATP adenosine triphosphate, $\mathrm{Ca}^{2+}$ calcium ion, $C a M K \mathrm{Ca}^{2+} /$ calmodulin-dependent protein kinase, $C K D$ chronic kidney disease, $\mathrm{Col}$ collagen, $C T G F$ connective tissue growth factor, $C y t C$ cytochrome $\mathrm{C}, C V$ cardiovascular, $E R S$ endoplasmic reticulum stress, ETC electron transport chain, $F G F$ fibroblast growth factor, GHRH growth hormone-releasing hormone, JNK c-Jun N-terminal kinases, ly lymphocyte, $m a$ macrophage, $M A P K$ mitogen-activated protein kinase, $m i R$ microRNA, mo monocyte, Mito mitochondrion, $N F-\kappa B$ nuclear factor- $\kappa \mathrm{B}, n g$ neutrophil granulocyte, $P A C A P 38$ pituitary adenylate cyclase-activating polypeptide 38 , $P A R P 1$ polyADP-ribose-polymerase 1, PECAM platelet endothelial cell adhesion molecule, ROS/RNS reactive oxygen and nitrogen species, TGF- $\beta$ tissue growth factor- $\beta, T N F-\alpha$ tumor necrosis factor- $\alpha$ 
and PDGF) promote myofibroblast differentiation, cardiomyocyte hypertrophy, the proliferation of endothelial cells and fibroblasts, leading to compensatory hypertrophy with increased collagen deposition and remodeling in the heart and vessel walls, and also stenosis in the vessel lumen [58]. With the exacerbated atherosclerosis and reduced capillary network, these processes may lead to myocardial hypoxia and chronic ischemia, potentially resulting in cell death and, ultimately, HF or IHD [87] (Fig. 3). Evidence suggests that chronic activation of the renin-angiotensin-aldosterone system (RAAS) and the sympathetic nervous system in HF also stimulates the inflammation and oxidative/nitrosative/ nitrative stress, which factors further aggravate each other [88, 89]. Angiotensin II has been reported to activate cardiac NADPH oxidase and, subsequently, the overproduction of ROS/RNS. The increased oxidative/nitrosative/nitrative stress triggers the production of pro-inflammatory mediators, including, e.g., IL-1, IL-6, TNF- $\alpha$, and TGF- $\beta$, contributing to cardiac remodeling and HF [90, 91] (Fig. 3).

\section{Compensatory cardiac hypertrophy in RIHD}

After RT-induced acute cell damage and death, a compensatory hypertrophy is initiated in the surviving cardiomyocytes to compensate for declined cardiac function due to the loss of cardiomyocytes. Chronic hypoxia, inflammatory pathways, and repetitive ischemia could play a role in the development of compensatory hypertrophy [31-34] (Figs. 1 and 3). Irradiation induces a significant increase in left ventricular wall thicknesses accompanied by reduced left ventricular inner diameters. In this early phase of HF, diastolic dysfunction develops with elevated left ventricular filling pressures and preserved ejection fraction (HFpEF) [33, 34, 92, 93]. It has also been reported that miR-212 [34], increased oxidative stress, TGF- $\beta$ signaling, and exchange protein activated by cAMP (Epac) could play an essential role in the development of cardiac hypertrophy after RT [32, 33]. Epac was shown to increase intracellular $\mathrm{Ca}^{2+}$ flux, activate hypertrophic signals such as the $\mathrm{Ca}^{2+} /$ calmodulindependent protein kinase II (CaMKII) and calcineurin, and induce fetal gene reprogramming independently of TGF- $\beta$ mediated fibrotic pathways [32].

\section{Cardiac fibrosis in RIHD}

Cardiac fibrosis is considered the main late cardiac side effect of RT, leading ultimately to HF with reduced ejection fraction (HFrEF) in the decompensated phase of HF (Figs. 1 and 3). It begins early after RT in parallel with the compensatory hypertrophy and might remain asymptomatic for years [39] (Figs. 2 and 3). Cardiac fibrosis is the result of abnormally increased extracellular deposition of collagen. The initiation stage of fibrogenesis is driven by the RT-induced primary vascular endothelial cell injury. The acute changes, occurring within a few hours after RT, are related to cell death and the resulting release of acute-phase inflammatory response molecules (e.g., PDGF, TGF- $\beta$, basic FGF, insulin-like growth factor [IGF], CTGF, IL-4, IL-13, IL-8, and MCP) [20, 43, 58]. The duration of the acute phase may be up to several days after the RT. Within 2-3 weeks after RT, fibrogenic effector cells, including fibroblasts, fibrocytes, tissue-specific pericytes, and myofibroblasts, are activated to differentiate into mature myofibroblasts in the second phase of fibrogenesis $[58,94]$. The activated and terminally differentiated myofibroblasts secrete a high amount of type I, III, and IV collagens, as well as $\alpha$-smooth muscle actin, into the extracellular matrix [43]. In this process, TGF- $\beta$ is considered a key factor in promoting the differentiation and mesenchymal cells to myofibroblasts. TGF- $\beta$ can activate the canonical SMAD2/3 and the non-canonical Rho/Rack profibrotic pathways, inhibit the collagenases, and stimulate the production of CTGF [20]. In the third phase of fibrogenesis, myofibroblasts produce a large range of extracellular proteins, primarily in an autocrine manner, which may last several weeks or months after the second phase. Myofibroblasts are permanently activated in the irradiated tissues even after repair of the initial injury. This process is driven mainly by TGF- $\beta$ and PDGF [95]. Another factor is the ROS/RNSinduced activation of the transcription factor NF- $\kappa B$. Its activation results in increased adhesion molecule, cytokine, and chemokine production [43] (Fig. 3). NF-KB was shown to be chronically upregulated in irradiated human arterial vascular cells from 4 to 500 weeks after RT suggesting that it might play a critical role in the transition from acute to chronic inflammation and fibrosis [52]. The last phase of fibrogenesis is the manifest myocardial fibrosis developing years or decades after the RT. The progressive and diffuse interstitial fibrosis leads to decreased tissue elasticity and contractility as well as chronic hypoxia by separating and replacing the cardiomyocytes. [20, 35]. Cardiac fibrosis ultimately results in cell death mechanisms, organ dysfunction, and HF leading to a decompensated stage (Fig. 3).

\section{Cellular senescence in RIHD}

Cellular senescence was traditionally considered a process to inhibit uncontrolled replication in proliferative cells [96]. Nowadays, it is thought that post-mitotic cells also develop a senescent-like phenotype [96]. Generally, senescent cells become flattened, enlarged, and irreversibly lose the ability of proliferation [96]. Senescent cells produce increased levels of ROS/RNS, which represent increased oxidative/ nitrosative/nitrative stress to neighboring cells. Typical senescent cells secrete a plethora of inflammatory mediators (e.g., cytokines and chemokines) and extracellular proteases, and the entity is named the senescence-associated 
secretory phenotype. This phenotype leads to chronic sterile inflammation and contributes to tissue remodeling [96, 97]. The role of senescent endothelial cells seems to be crucial in the development of RIHD (Fig. 3). RT-induced endothelial senescence may involve the activation of IGF1/ phosphatidylinositol-3-kinase (PI3K)/Akt-mTOR pathway acting upstream of $\mathrm{p} 53 / \mathrm{p} 21, \mathrm{p} 38, \mathrm{NF}-\mathrm{\kappa B}$, and TGF- $\beta$ type 1 receptor ALK5. The induction of ERS and repression of telomerase reverse transcriptase are also characteristics of senescent endothelial cells $[96,97]$. Due to the decreased NO bioavailability, senescent endothelial cells are incapable of regulating vasodilation, resulting in accelerated atherosclerosis and hypertension (Fig. 3). They are pro-inflammatory, pro-thrombotic, and pro-atherogenic due to their increased production of various inflammatory cytokines, adhesion molecules, and plasminogen activator inhibitor-1 (PAI-1), and decreased levels of thrombomodulin (Fig. 3). They are also incapable of regeneration, leading to reduced density of cardiac capillaries and small coronary arterioles. The capillary rarefaction can lead to chronic cardiac hypoxia contributing to the RT-induced HF and IHD $[96,97]$.

\section{Diagnosis and follow-up of RIHD in patients}

If needed, the early diagnosis and control of RIHD are essential since medical therapy or intervention may be of benefit. Control of RIHD should start with identifying individuals at risk for RIHD by registering heart and coronary artery dosimetry data. The existence of other cardiac risk factors such as history, age, and the use of chemotherapy, should be registered. In individuals at risk, clinical history and baseline measurement of cardiac function should be recorded. Regular monitoring of symptoms/signs and cardiac function should start after RT, while in non-risk patients, the patient's and physician's alertness is sufficient [13, 24]. There has been an interest in testing various biomarkers of myocardial injury or HF, including troponin I, troponin T, B-type natriuretic peptide, or inflammatory cytokines such as growth differentiation factor-15 and C-reactive protein. These may be used for the detection and follow-up of HF most often related to medical therapies, but only as a complementing tool of other diagnostic tools [98]. Cardiac imaging methods include echocardiography, nuclear imaging, cardio-CT, or MRI to serve better diagnosis [13]. Nevertheless, 2D speckle tracking echocardiography seems to be a sensitive and highly specific clinical approach for the detection of early subclinical heart abnormalities [98]. Cardiac SPECT perfusion scanning was reported to detect injury as early as a few months after RT [28]. The choice of the method may also depend on availability. For consistency reasons, the same expert is preferred to follow the case using the same diagnostic method. Different guidelines exist for the management of RIHD, including the follow-up of cancer patients after RT [12, 13, 21, 24, 99, 100]. During followup, careful exploration of symptoms (notably, radiogenic IHD presents relatively often silent), repeated ECG, stress and contrast echocardiography, 3D echocardiography, stress perfusion imaging, tissue Doppler imaging, and screening for coronary calcium deposits might be applied.

Onco-cardiology follow-up in everyday practice is shown in Fig. 4. All guidelines recommend the specification of the risk-status, preferably before starting oncological treatments or before outlining individual follow-up strategies [12, 13, 24]. For that, heart dose, the use of toxic oncological treatments, comorbidities, and age should be considered. According to the risk level, follow-up should start immediately or many years after the RT. In high-risk patients (a mediastinal dose of $>30 \mathrm{~Gy}$, or if anthracyclines were also given, etc.) monitoring should start 1-2 years post-irradiation and continue every 2 years thereafter; a great emphasis should be given to correcting risk factors. In low-risk cases, regular follow-up performed every $2-5$ years started 5 years after the RT is considered sufficient. For the routine follow-up of asymptomatic patients, ECG and echocardiography are used. During follow-up, careful attention should be paid to medical history; if symptoms or suspicious signs develop, imaging and functional studies should be performed as previously described $[12,13,24]$.

\section{Prevention and therapy of RIHD}

Currently, there are two main strategies to lessen the burden caused by radiogenic heart sequelae. One is to prevent heart exposure as much as possible by applying new RT technologies and protocols [101]. Second, identifying those risk patients whose surveillance after RT is crucial, sometimes with comprehensive multimodality imaging-based screening protocols if necessary; the early diagnosis and non-specific management of radiation heart damage may effectively improve outcomes. A third possibility would be the application of pharmacons to protect the heart from radiation-induced damage. However, at present, no specific pharmaceutical agent is approved for the prevention or treatment of RIHD in the clinics. Nevertheless, several lines of evidence obtained in preclinical or clinical studies suggest that a number of pharmacological agents might be effective for the treatment of RIHD.

\section{Prevention of RIHD by cardiac dose-sparing techniques}

It is mandatory to individually estimate the net benefit of RT before its start by balancing the gains against the greatness of cardiac dose and the patient's background cardiovascular 
Fig. 4 Algorithm of cardiovascular follow-up after thoracic RT. $C A D$ coronary artery disease, $E C G$ electrocardiography, echo: echocardiography, HER2 human epidermal growth factor receptor, $L A D$ left anterior descending artery, $R T$ radiotherapy

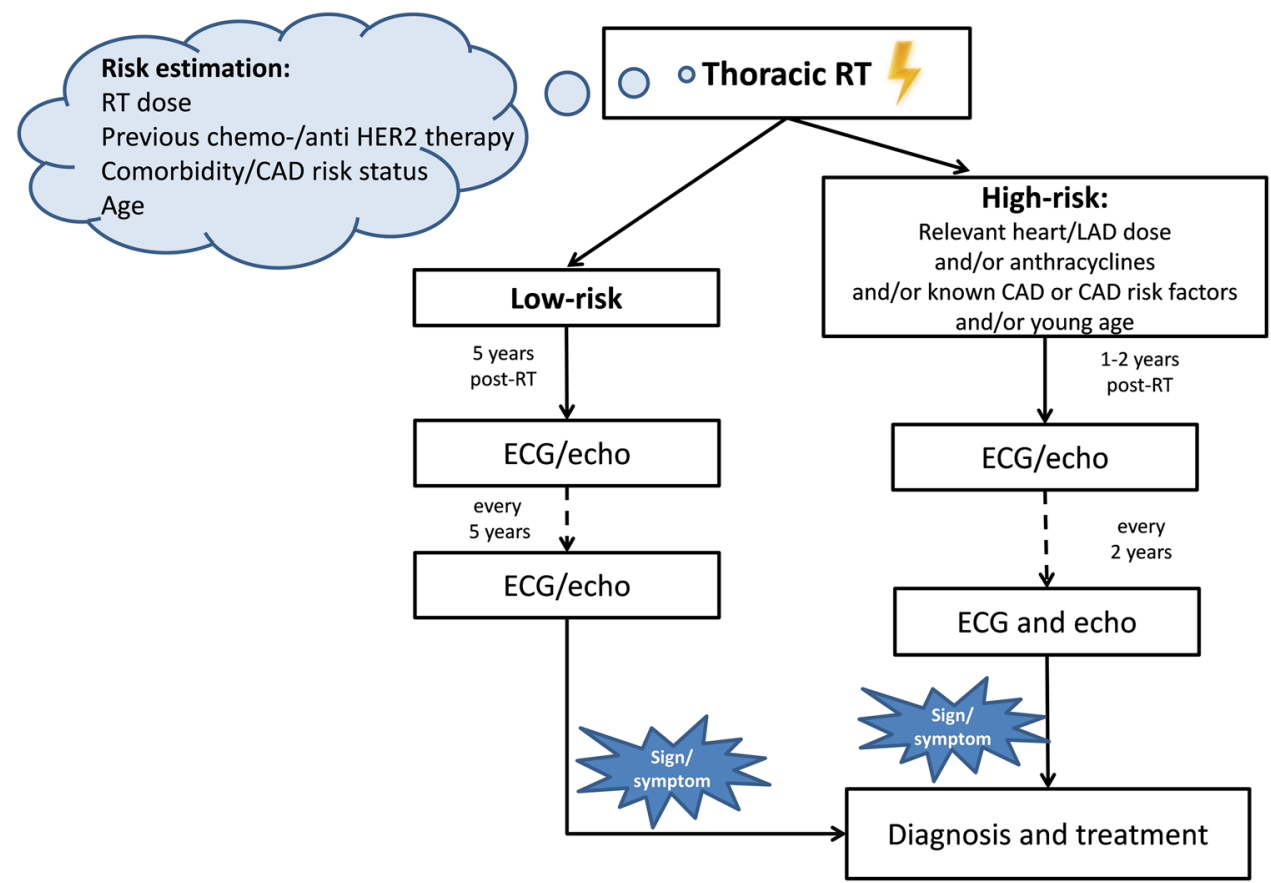

risk in the absence of RT [102]. There are many approaches to protect the heart from radiation exposure in breast cancer patients [102]. Prone positioning during RT reduces heart doses in about $2 / 3$ of the patients [103-105], while the deep-inspirational breath-holding (DIBH) technique is advantageous in an even higher proportion of patients [106, 107]. Both methods operate by separating the heart and the radiation fields. Intensity-modulated radiation therapy (IMRT) and proton irradiation are advanced techniques not yet widely applied while reducing the volume to be irradiated during partial breast irradiation (PBI), or the omittance of RT are options in low-risk of cancer recurrence cases. For the best risk-benefit ratio, the selection of individually tailored techniques and RT modality is needed [103, 104]. In non-breast cancer patients needing RT to the chest, developed techniques such as the IMRT/volumetric modulated arc radiotherapy (VMAT), cyberknife, or stereotactic radiosurgery are all based on image-guidance and particle RT. Sometimes breathing-control/gating ensure precise targeting and best protection of normal tissues [106]. Special consensus guidelines stressing the use of modern techniques, and selective RT have been elaborated for the modern RT of lymphoma patients [108]. RT guidelines with similar concepts have been published for lung cancer [109] and oesophageal cancer [110].

\section{Prevention and therapy of RIHD with pharmacological agents}

Although many agents have been tested for the prevention of radiation damage, none of them yet gained registration with this indication. Most of our knowledge in this field is experimental only. The group of the so-called radioprotectors has anti-oxidant and/or anti-inflammatory properties being administered as molecular preventive strategies before radiation exposure [44]. The so-called mitigators are administered during or shortly after the irradiation with the aim of ameliorating the radiation injury of normal tissues [44]. A third approach is starting the protectant several weeks after the radiation exposure. The pharmacological treatment of RIHD initiated after the completion of the RT has a clear benefit with the advantage of not interfering with the efficacy of cancer therapy but, only a few preclinical studies tested this approach. Despite the lack of specific treatments for RIHD in clinical practice, some recommendations exist on using standard therapies in the radiation heart sequelae indication (e.g., HF or IHD) [12, 13]; furthermore, some promising novel approaches also exist. This section collects well-known drugs and promising novel agents mostly tested in rodent RIHD models. The description of the potential side effects of the well-known drugs is out of the scope of this review.

\section{Anti-oxidants}

Since the production of ROS/RNS is a crucial element in the development of acute and chronic RIHD, testing antioxidants seems logical.

$\alpha$-tocopherol (vitamin E)

Administration of a single dose of tocotrienols $24 \mathrm{~h}$ before the cardiac irradiation preserved the $\mathrm{Bax} / \mathrm{Bcl} 2$ ratio and prevented mitochondrial permeability transition and 
RT-induced alterations in the mitochondrial respiration in rats 2 weeks after RT [111] (Table 2). However, the single dose of tocotrienols could not improve the cardiac remodeling 28 weeks after RT [111]. In another study, the phosphodiesterase inhibitor pentoxifylline plus $\alpha$-tocopherol given daily and started 1 week before the RT or 3 months after the RT reduced the collagen deposition in rats 6 months after RT [93] (Table 2). Daily administration of $\alpha$-tocopherol plus pentoxifylline for 6 months started 3 days before the RT reduced collagen deposition and TGF $\beta 1$ levels in a rat model 6 months after the RT [112] (Table 2). However, the daily administration of $\alpha$-tocopherol plus pentoxifylline for 3 months started 3 days before the RT could not reduce the cardiac remodeling 6 months after the RT [112] (Table 2). In another study, the daily application of pentoxifylline and $\alpha$-tocopherol 3 months after the RT did not alter cardiac fibrosis and left ventricular expression of vWF, neuregulin-1, hypertrophic, and fibrotic signal mediators in rats 6 months after the RT [113]. However, the cardiac number of macrophages and mast cells was reduced [113] (Table 2).

Amifostine (Ethyol)

The inactive prodrug amifostine (WR-2721) is a phosphorylated thiol, which can be converted to its active form (WR-1065) by alkaline phosphatase-catalyzed dephosphorylation in the vascular endothelial cells [114]. It has been demonstrated that amifostine protects normal tissues from both acute and chronic damage without interfering with the effects of RT on the tumor $[115,116]$. Several preclinical studies have shown that a single dose of amifostine given 15-30 min before irradiation could be protective against RT-induced cardiac fibrosis, myocardial dysfunction, and vascular damage 100 days or 6 months after RT [114, 117, 118] (Table 2).

\section{Natural products}

Several natural products, including hesperidin, curcumin, melatonin, caffeic acid phenylethyl ester, black grape juice, and the ginger component zingerone, have been proposed as radioprotective agents due to their antioxidant and/or antiinflammatory properties against RIHD as reviewed recently [119].

\section{Anti-inflammatory drugs}

Inflammation plays a major role in the development of RIHD, so it is not surprising that attenuation of the inflammatory response may beneficially affect the cardiac consequences of RT.

\section{Colchicine}

Colchicine is known to inhibit microtubule polymerization. Therefore, it can inhibit mitosis, neutrophil motility, and decrease platelet aggregation. The anti-inflammatory and platelet aggregation inhibiting properties of colchicine are suggested to be protective against RIHD [120]. However, there is no experimental or clinical evidence available in the literature for its use in RIHD.

Steroidal anti-inflammatory drugs

Reeves et al. reported that the steroidal anti-inflammatory drugs, dexamethasone, and methylprednisolone given $2 \mathrm{~h}$ prior to heart irradiation and every $24 \mathrm{~h}$ for 3 consecutive days reduced the cardiac fibrosis and hydroxyproline content in male rabbits 100 days after RT [121, 122] (Table 2).

Non-steroidal anti-inflammatory drugs (NSAIDs)

Administration of the non-selective NSAID ibuprofen administered $2 \mathrm{~h}$ prior to heart irradiation and for 2 days thereafter reduced fibrosis, pericarditis, pericardial effusions, and improved survival in male rabbits 100 days after RT [122] (Table 2). It has been reported that the use of various several non-selective COX inhibitors (e.g., ibuprofen, diclofenac, and naproxen) and selective COX-2 inhibitors (e.g., celecoxib) increased the risk of AMI [123]. Therefore, several NSAIDs are contraindicated among patients with CVDs. However, there is limited data available about the effects of NSAIDs on the risk of AMI in patients treated with thoracic RT. Uehara et al. investigated the effects of NSAIDs, including diclofenac, etodolac, indomethacin, ketoprofen, meloxicam, and rofecoxib, on RT-induced expression of ICAM-1, VCAM-1, E-selectin, and COX-2 in human umbilical vein endothelial cells (HUVECs) [124]. They found that indomethacin, diclofenac, and meloxicam given $1 \mathrm{~h}$ before RT highly upregulated the RT-induced expression of ICAM-1 and COX-2 in HUVECs, suggesting the potentiating effects of these NSAIDs on RT and the increased risk for AMI after thoracic RT [124]. The COX-2 inhibitor celecoxib has been reported to act synergistically with RT in cancer cells since it attenuates tumor growth and expression of cell proliferation markers and induces apoptosis in tumor cells [125]. The increased expression of adhesion molecules and apoptotic effects of celecoxib or several NSAIDs might be responsible for the increased risk for AMI after RT. However, further preclinical and clinical studies are needed to evaluate the effects of NSAIDs on the development of RIHD.

\section{Cardioprotective drugs}

Cardioprotective drugs are used to lower the severity of consequences due to CVD risk factors under various stress conditions. The application of such drugs in the case of chest RT may be useful.

\section{Trimetazidine}

Trimetazidine is an antianginal drug that inhibits the beta-oxidation of fatty acids by blocking mitochondrial longchain 3-ketoacyl coenzyme A thiolase [126]. Trimetazidine also has anti-oxidant, anti-apoptotic, and inflammatory effects and may improve endothelial function [127]. Daily trimetazidine treatment started 1 week before or after chest 


\begin{tabular}{|c|c|c|c|c|c|c|c|c|c|}
\hline $\mid \begin{array}{l}\dot{\infty} \\
\approx \\
\approx\end{array}$ & $\Xi$ & $\bar{\alpha}$ & $\stackrel{\Xi}{\Xi}$ & $\stackrel{\bar{m}}{\Xi}$ & $\Xi$ & $\stackrel{\Xi}{\Xi}$ & $\stackrel{\infty}{\Xi}$ & $\stackrel{\bar{\Xi}}{\Xi}$ & $\overline{\mathbb{J}}$ \\
\hline & 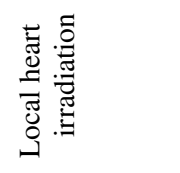 & 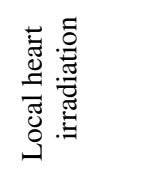 & 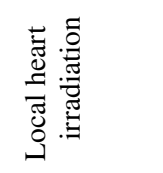 & 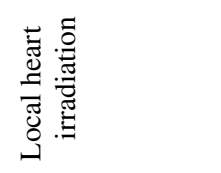 & 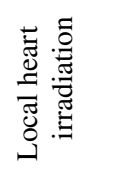 & 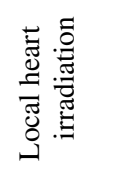 & 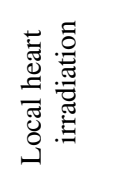 & 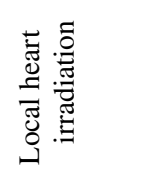 & 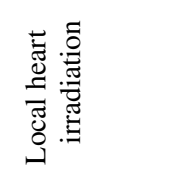 \\
\hline 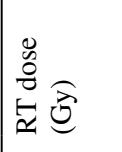 & $\begin{array}{l}\vec{U} \\
\vec{N}\end{array}$ & $\begin{array}{l}\vec{J} \\
a \\
x \\
i\end{array}$ & $\begin{array}{l}\vec{U} \\
\text { ते }\end{array}$ & $\vec{\mho}$ & $\begin{array}{l}\overrightarrow{0} \\
\qquad\end{array}$ & $\begin{array}{l}\widehat{U} \\
\infty \\
\infty\end{array}$ & 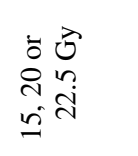 & $\begin{array}{l}\vec{U} \\
\stackrel{\sim}{ }\end{array}$ & $\begin{array}{l}\vec{U} \\
\stackrel{N}{ }\end{array}$ \\
\hline 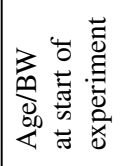 & 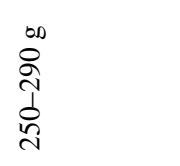 & $\begin{array}{l}\infty \\
\stackrel{\Pi}{1} \\
1 \\
\infty \\
\infty\end{array}$ & $\begin{array}{l}\frac{4}{3} \\
\pm \\
I \\
\simeq\end{array}$ & $\begin{array}{l}\infty \\
\text { o } \\
\text { i } \\
\text { ते } \\
\text { ते }\end{array}$ & 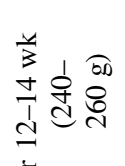 & 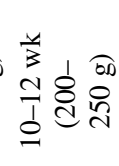 & \begin{tabular}{l}
$\frac{7}{0}$ \\
0 \\
3 \\
3 \\
\cline { 1 - 1 }
\end{tabular} & 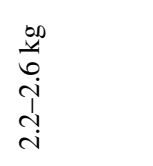 & 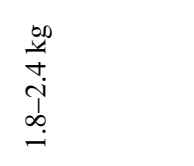 \\
\hline 䚄亗 & 吾 & 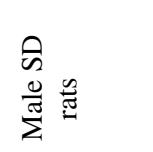 & 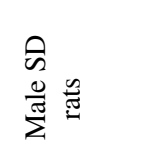 & 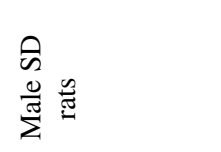 & 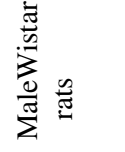 & 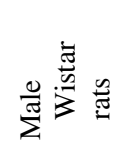 & 总 & 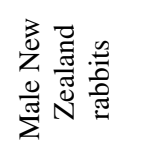 & 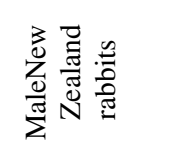 \\
\hline 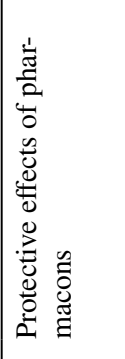 & 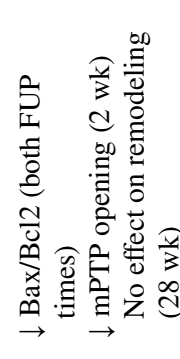 & 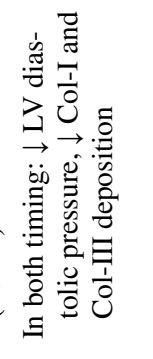 & 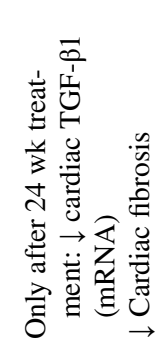 & 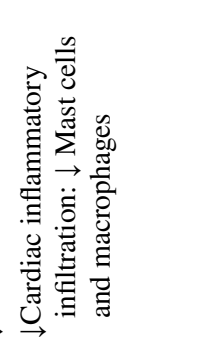 & 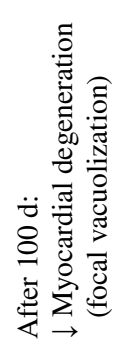 & 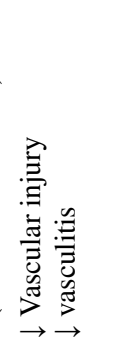 & 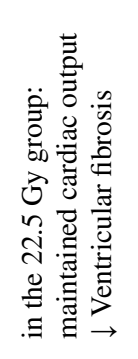 & 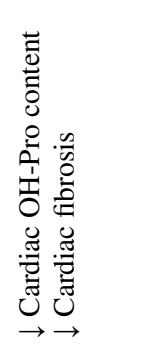 & 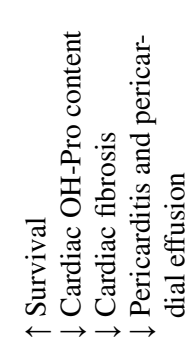 \\
\hline 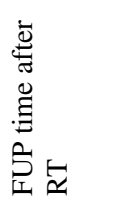 & $\begin{array}{l}4 \\
3 \\
0 \\
N \\
\tilde{0} \\
\text { N }\end{array}$ & छ్ & $\begin{array}{l}\frac{y}{3} \\
\stackrel{+}{d}\end{array}$ & छ & 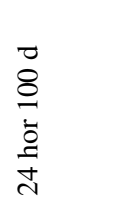 & ‡ & छ & 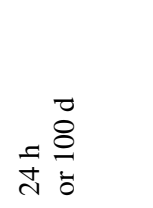 & 응 \\
\hline 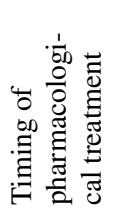 & 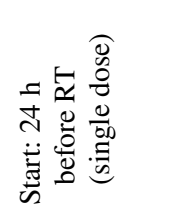 & 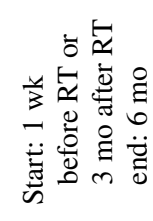 & 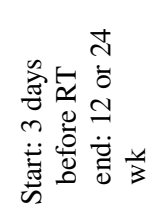 & 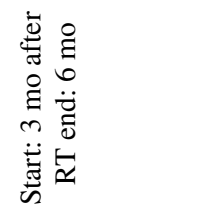 & 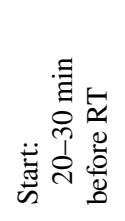 & 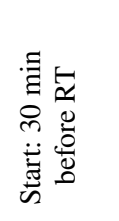 & 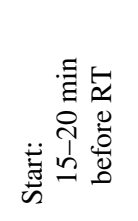 & 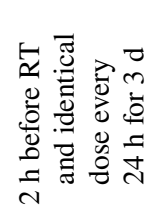 & 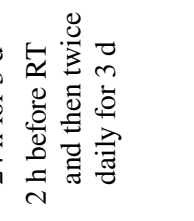 \\
\hline 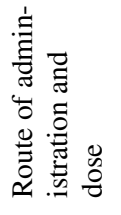 & 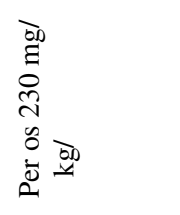 & 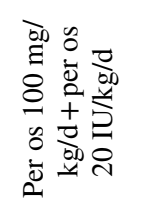 & 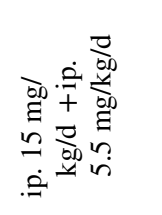 & 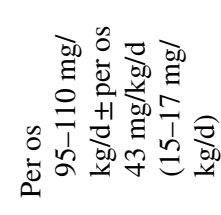 & 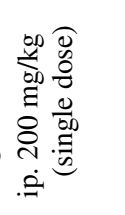 & 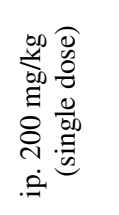 & 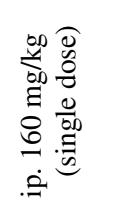 & $\begin{array}{l}\vec{\partial} \\
b 0 \\
\Xi \\
n \\
\geq \\
\geq\end{array}$ & 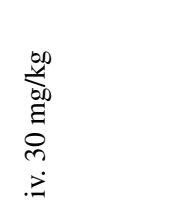 \\
\hline 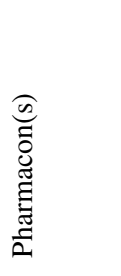 & 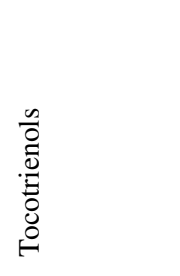 & 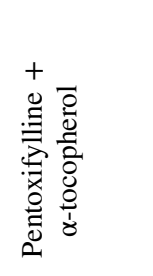 & 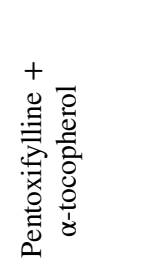 & 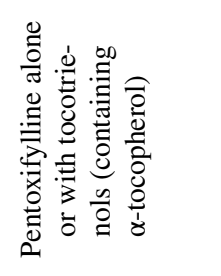 & 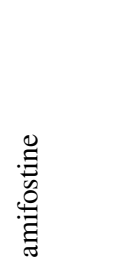 & 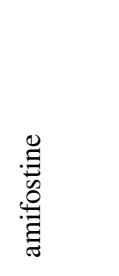 & 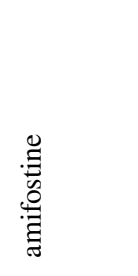 & 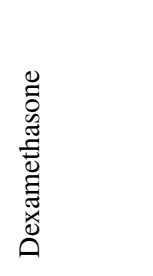 & 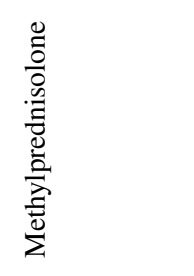 \\
\hline 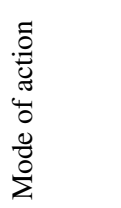 & 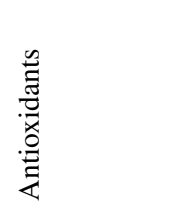 & 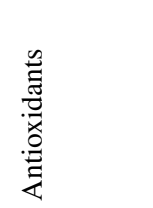 & 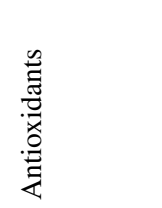 & 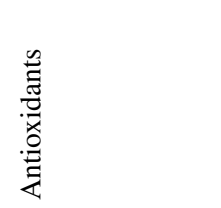 & 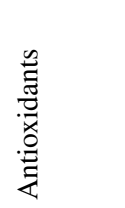 & 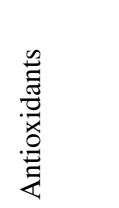 & 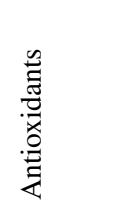 & 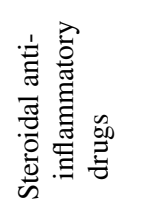 & 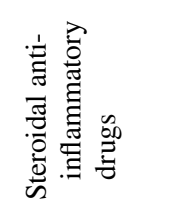 \\
\hline
\end{tabular}




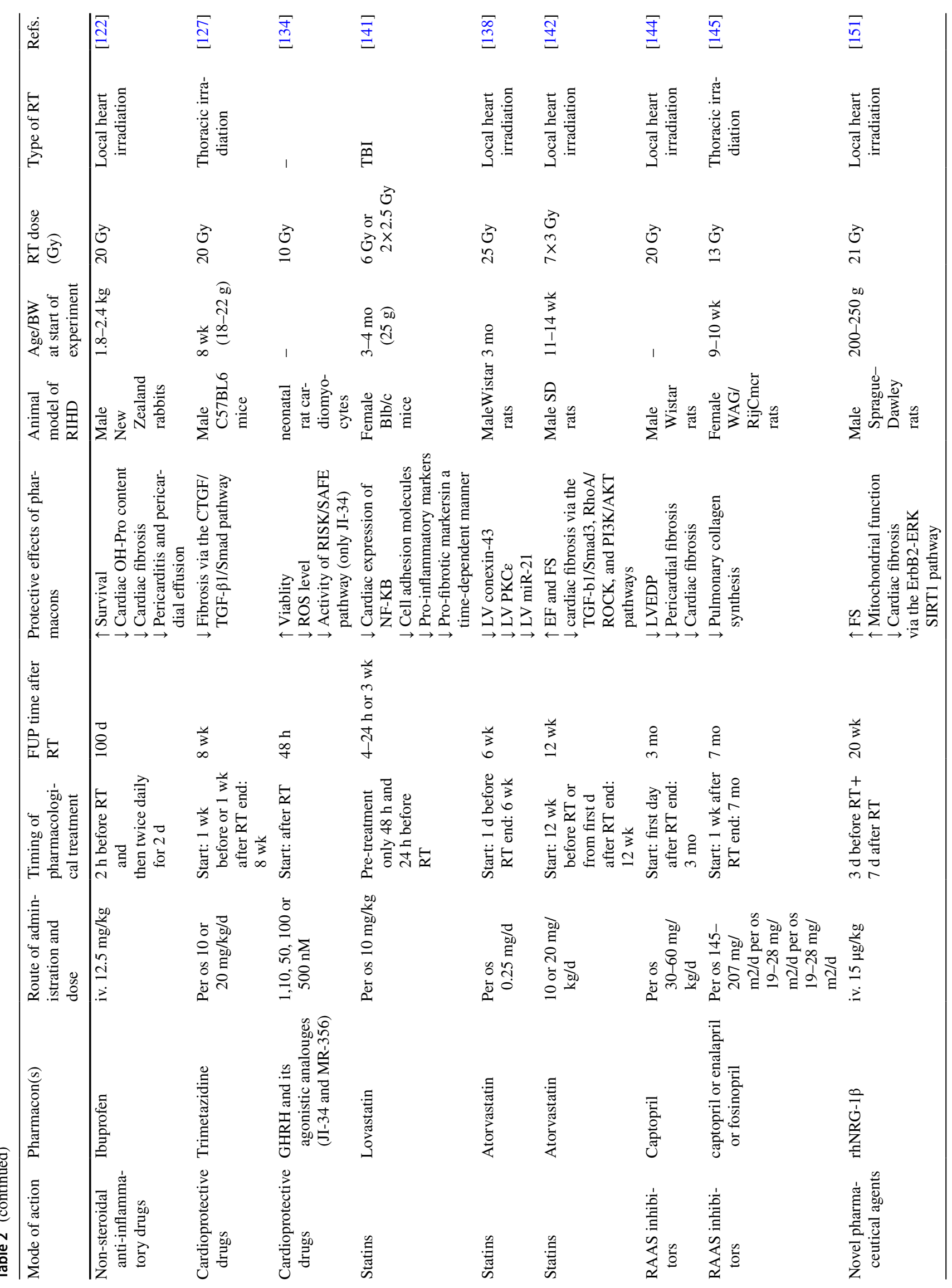




\begin{tabular}{|c|c|c|c|}
\hline$\frac{\dot{\Phi}}{\mathscr{\Xi}}$ & $\mid \begin{array}{l}\stackrel{0}{2} \\
\varrho\end{array}$ & $\stackrel{\bar{n}}{\varrho}$ & $\underset{\widetilde{\sigma}}{\varrho}$ \\
\hline 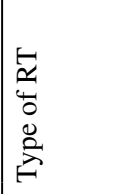 & 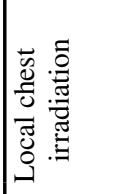 & 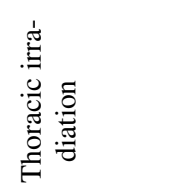 & 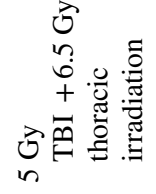 \\
\hline 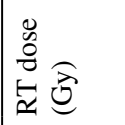 & $\begin{array}{l}\overrightarrow{0} \\
0 \\
0\end{array}$ & $\begin{array}{l}\widehat{U} \\
\Xi\end{array}$ & 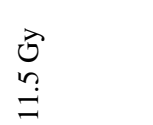 \\
\hline 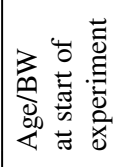 & $\begin{array}{l}\frac{4}{3} \\
\frac{1}{1} \\
0\end{array}$ & 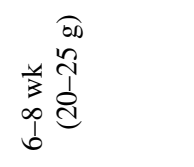 & $\begin{array}{l}y \\
\overrightarrow{3} \\
0 \\
b\end{array}$ \\
\hline 焉容 & 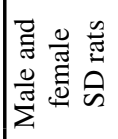 & 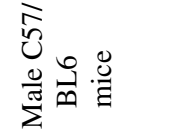 & 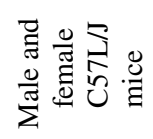 \\
\hline 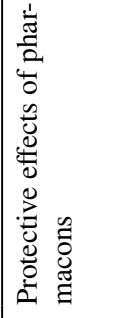 & 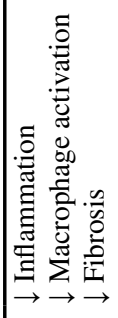 & 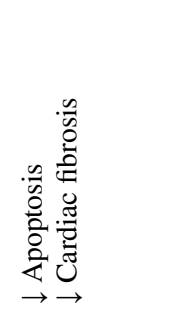 & 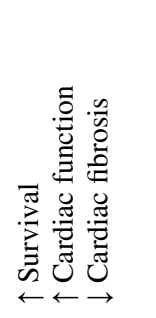 \\
\hline 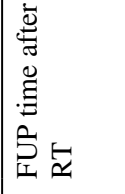 & $\begin{array}{l}4 \\
3 \\
\infty \\
-\infty\end{array}$ & $\begin{array}{l}\stackrel{\infty}{\vec{d}} \\
\vec{\lambda}\end{array}$ & ‡ \\
\hline 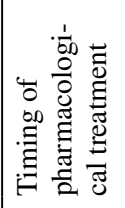 & 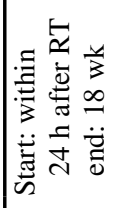 & 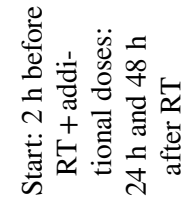 & 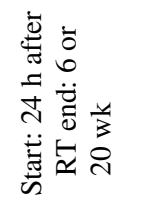 \\
\hline 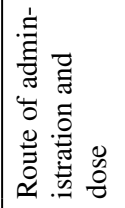 & 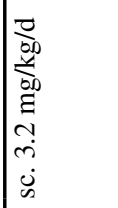 & $\begin{array}{l}\overline{5} \\
8 \\
\frac{8}{100} \\
\frac{3}{0} \\
0 \\
\dot{ }\end{array}$ & 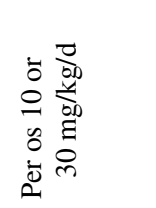 \\
\hline 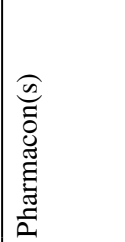 & 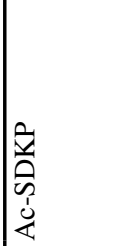 & 总 & 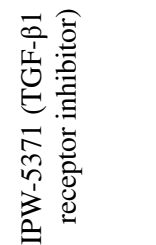 \\
\hline 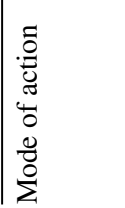 & 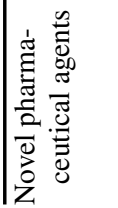 & 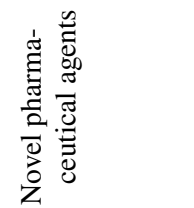 & 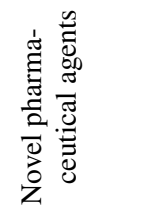 \\
\hline
\end{tabular}

irradiation reduced cardiac fibrosis via the CTGF/TGF- $\beta 1 /$ Smad $2 / 3$ axis 8 weeks after the RT [127] (Table 2).

Growth hormone-releasing hormone (GHRH) and its agonists

The growth hormone-releasing hormone (GHRH) and its agonistic analogs are involved in the metabolism of reactive oxygen and nitrogen species and the proliferation and survival of a series of normal cells, including cardiomyocytes [128-130]. The administration of GHRH or GHRH analogs improved contractile recovery, ventricular remodeling during reperfusion, and reduced infarct size [131-133]. Similarly, two GHRH agonists, JI-34, and MR-356 showed increased viability and reduced ROS levels $48 \mathrm{~h}$ after irradiation in neonatal rat cardiomyocytes [134] (Table 2). However, only JI-34 could reduce the activity of the hypertrophic RISK/SAFE pathway [134] (Table 2).

\section{Anti-atherosclerotic drugs, standard IHD and HF regimens}

Recent position papers of the European Society of Cardiology and the German Cardiac Society summarize all the possible toxic effects of anti-cancer therapies on cardiovascular health comprehensively and stress the need for cardio-oncology services $[12,13]$. Endothelial dysfunction and atherosclerosis play an important role in the development of RIHD. Age and cardiovascular risk factors can further accelerate the atherosclerotic process in long-term cancer survivors. Hence, the attenuation of endothelial dysfunction and atherosclerosis might lower the cardiovascular consequences of RT. Cancer patients presenting with clinical HF or IHD during or following cancer treatment need access to medical therapy with standard HF regimens or sometimes transcatheter or open surgical interventions [13]. Combined management with the control of age-related comorbidities and cardiovascular risk factors (such as hypertension, hypercholesterolemia, and diabetes) is crucial [135].

\section{Statins}

The widely used statins are blood cholesterol-lowering drugs that inhibit the key enzyme, 3-hydroxy-3-methylglutaryl coenzyme A (HMG-CoA) reductase, playing an important role in the endogenous cholesterol synthesis [84]. Therefore, statins are used in the treatment of hypercholesterolemia and atherosclerosis [84]. Recent studies showed that statins could also reduce cardiac oxidative/ nitrosative/nitrative stress, acute inflammatory reactions, and fibrosis via different mechanisms [136-138]. Notably, in RIHD, the inhibition of RhoA GTPase, which plays a crucial role in endothelial cell migration, might be of benefit [139]. Statins can also decrease the cardiac endothelial cell permeability via activating ERK5 and increase the release of the vasodilator NO [140]. Ostrau et al. showed that single doses of lovastatin given 48 and $24 \mathrm{~h}$ before RT reduced the expression of NF- $\mathrm{KB}$, cell 
adhesion molecules, pro-inflammatory and pro-fibrotic markers in a time-dependent manner from $24 \mathrm{~h}$ to 3 weeks after RT in rats [141] (Table 2). In a rat model of RIHD, daily administration of atorvastatin started 1 day before RT decreased the expression of the profibrotic miR-21, connexin-43 and PKC $\varepsilon$ in the left ventricle 6 weeks after the RT [138] (Table 2). Zhang et al. reported that daily atorvastatin treatment started 3 months before or 1 day after the RT improved cardiac function and reduced fibrosis via the repression of TGF- $\beta 1, \mathrm{Smad} 3 / \mathrm{p}-\mathrm{Smad} 3, \mathrm{Rho} /$ ROCK, p-Akt, and fibronectin in rats [142] (Table 2).

\section{RAAS inhibitors}

RAAS plays a pivotal role in the development of CVDs, including hypertension, atherosclerosis, AMI, cardiac hypertrophy, and HF, via different systemic and tissue-specific effects [143]. The common point in the pathophysiology of the various CVDs is the microvascular injury that leads to subsequent myocardial ischemia and late fibrous remodeling [143]. Clearly, the pathophysiology of RIHD is similar to that of other etiologies induced by angiotensin II and aldosterone. Cardiac concentrations of angiotensin II and aldosterone were dose-dependently increased 3 months after heart irradiation in rats [143]. Importantly, the daily administration of the angiotensin-converting enzyme (ACE) inhibitor captopril started on the first day after the RT ameliorated the perivascular and cardiac fibrosis as well as the diastolic dysfunction 3 months after the RT in rats [144] (Table 2). Another study demonstrated that daily treatments of three structurally-different ACE inhibitors, captopril, enalapril, and fosinopril, given 1 week after thoracic RT reduced pulmonary collagen synthesis 7 months post-radiotherapy in rats [145] (Table 2). Although these data are interesting, prospective studies evaluating the efficacy of ACE inhibitors in patients undergoing thoracic RT are lacking in the literature. The PRADA clinical trial enrolling 130 women with early breast cancer demonstrated that adjuvant, anthracycline-containing regimens with or without trastuzumab and RT were associated with a modest reduction of the left ventricular ejection fraction (LVEF). This decline in LVEF was significantly alleviated by the concomitant administration of the angiotensin receptor blocker (ARB) candesartan [146]. In contrast, a retrospective clinical study enrolling 76 patients undergoing coronary artery stenting after thoracic RT ( $>30 \mathrm{~Gy}$ ) found that ACE inhibitors or ARBs and higher MHD were related to lower overall survival since cancer diagnosis [26]. In order to clarify whether RAAS inhibitors may be protective against RIHD, clinical trials enrolling a large number of patients are required for widening the indication of this otherwise routinely used medication of heart failure.

\section{Novel pharmaceutical agents}

\section{Recombinant human neuregulin-1 $\beta($ rhNRG-1 $\beta)$}

Neuregulin-1 $\beta$ (NRG-1 $\beta$ ) binds to the tyrosine kinase receptors of the ErbB family, i.e., ErbB2, ErbB3, and ErbB4 in the heart [147]. NRG-1 $\beta$ is critical for cardiac development and repair, and recombinant forms are currently being assessed in clinical trials as possible therapeutic agents for systolic HF even [NCT03388593, NCT04468529]. Indeed, numerous preclinical studies confirmed the anti-inflammatory, anti-remodeling, and anti-fibrotic effects of NRG-1 in the heart [148-150]. RhNRG- $1 \beta$ given 3 days before and 7 days after heart irradiation decreased RT-induced myocardial fibrosis and cardiomyocyte hypertrophy while preserving cardiac function via the ErbB2-ERK-SIRT1 signaling pathway 20 weeks after the RT in rats [151] (Table 2). In preclinical studies, NRG-1 was also protective against doxorubicin-induced or trastuzumab-induced cardiotoxicity, a common unwanted side-effect related to drugs used in breast cancer patients $[152,153]$. Although some studies have proposed that NRG1 may promote tumor growth, NRG1 could also act as a tumor suppressor in breast cancer $[154,155]$. Further studies are needed to clarify the effects of rhNRG- $1 \beta$ on the tumor growth-stimulating potential of rhNRG-1 $\beta$.

\section{N-acetyl-Ser-Asp-Lys-Pro (Ac-SDKP)}

Ac-SDKP is a ubiquitous endogenous peptide originating from thymosin- $\beta 4$, which is essential for epicardial progenitor mobilization and neovascularization [156]. Ac-SDKP showed anti-fibrotic and macrophage inhibitory effects via inhibiting the expression and activity of a carbohydratebinding surface protein, Mac-2 (galectin-3), in preclinical models [157, 158]. Ac-SDKP administered daily for 18 weeks after thoracic RT inhibited inflammation, fibrosis, and reduced macrophage activation in rats [156] (Table 2).

Pituitary adenylate cyclase-activating polypeptide 38 (PACAP38)

The endogenous peptide PACAP38 is a member of the secretin/vasoactive intestinal peptide (VIP) family. It has anti-inflammatory, anti-apoptotic, and antioxidant effects in cardiomyocytes $[159,160]$. PACAP38 was radioprotective in $\mathrm{H} 9 \mathrm{c} 2$ cardiomyoblasts via anti-apoptotic effects and the overexpression of the nuclear factor erythroid 2-related factor 2 (NRF2), which is a key factor in the expression of antioxidant enzymes [159]. PACAP38 given $2 \mathrm{~h}$ before irradiation, and at $24 \mathrm{~h}$ and $48 \mathrm{~h}$ after irradiation reduced apoptosis and cardiac fibrosis 21 days after the RT in male C57BL6 mice [159] (Table 2).

Potential anti-inflammatory and anti-fibrotic biological therapies

A common mechanism in the pathophysiology of HF and IHD of non-radiation etiology is chronic inflammation and fibrosis. So far, no anti-inflammatory or anti-fibrotic 
biological therapy has been tested in RIHD in clinical trials. However, some anti-inflammatory agents, including, e.g., the IL-1 receptor antagonist anakinra (clinical trials NCT03797001, NCT01175018, and NCT02547766) or the IL-6 receptor antagonist tocilizumab (clinical trial NCT01491074), have been already tested against postinfarction remodeling and HF in phase 2 clinical trials. Interestingly, the human anti-CTGF antibody (FG-3019) started at different time points before or after thoracic irradiation ameliorated the pulmonary remodeling in a mice model [161]. However, anti-CTGF antibodies have not been tested in the clinical phase in RIHD yet. The TGF- $\beta$ receptor-1 antagonist IPW-5371 administered orally $24 \mathrm{~h}$ after the radiation exposure and daily after that for 6 or 20 weeks was reported to mitigate the injury of RT ( 5 Gy total body irradiation plus 6.5 Gy thoracic irradiation) in C57BLJ mice [162]. IPW-5371 treatment for both 6 and 20 weeks improved survival. The 20 -week therapeutic regimen preserved arterial oxygen saturation with significant decreases in breathing frequency. It reserved the cardiac contractile function and ameliorated cardiac and pulmonary fibrosis [162]. IPW-5371 treatment decreased p-Smad3 tissue levels, confirming the effect of IPW-5371 on TGF- $\beta$ signaling [162] (Table 2). IPW-5371 is not yet in the clinical phase, but another TGF- $\beta 1$ receptor inhibitor, the orally bioavailable galunisertib (LY2157299), has already been tested in phase II clinical trials in metastatic breast cancer patients in combination with RT (NCT02538471), hepatocellular carcinoma (NCT02178358), and pancreatic cancer (NCT01373164).

\section{Cardiac-specific drug delivery}

Radioprotective agents may interfere with the anti-cancer effects of RT. Therefore, the development of cardiacspecific drug delivery techniques (e.g., liposomes, polymeric micelles, biodegradable nanoparticles, dendrimers, exosomes, plasmids, or other vectors) [163]. would be of interest in order to selectively protect the heart from ionizing radiation and thus preventing RIHD. Several drugs, including VEGF delivered by plasmids or adenoviruses to the heart, have already been tested in HF and AMI in clinical trials (NCT03409627, NCT01002430, NCT04125732, respectively). Unfortunately, up to now, no major breakthrough has been achieved in the field of targeted drug delivery for the prevention of RIHD.

\section{Gene expression regulators as potential new therapeutic targets: non-coding RNAs}

The gene expression is regulated at different levels, including the post-transcriptional regulation by non-coding RNAs (ncRNAs). The ncRNAs are classified as $i$ ) longer ncRNAs such as long non-coding RNAs (lncRNAs) and circular RNAs (circRNAs), ii) and short ncRNAs (19-22 nucleotides) such as microRNAs (miRs) and small interfering RNAs (siRNAs) [164]. At present, literature data are available on the role of miRs only in the development of RIHD. miRs are thought to be tissue-specific fine-tuners of gene expression in biological processes, including those related to oxidative/nitrative stress, cell death, cell proliferation and development, and inflammation [165]. Hence, dysregulation of miRs in pathological processes, including RIHD, may alter whole gene networks rather than single genes. The major difference between miRs and siRNAs is that siRNAs are highly specific for one mRNA target, whereas miRs have multiple targets. Consequently, miR replacement or blockade with anti-sense inhibition therapy may offer a new approach to treat diseases by modulating complex gene pathways [166]. However, at present, the use of miRs as therapeutic targets or biomarkers has many limitations. A specific miR can target several mRNAs, and different miRs can target a particular mRNA in many tissue types. Therefore, potentially harmful effects of miR-based drugs (antagomiRs or agomiRs) could originate not only from off-target side effects (e.g., unwanted gene expression changes) but also from on-target side effects in non-targeted and non-diseased tissues [167]. In pre-clinical studies, cellular senescence-associated miR-34 [168], and pro-fibrotic miR-21 [169] were repressed, and the anti-fibrotic miR-15 [169] was overexpressed in the heart. These miRs seems to be promising in the future treatment of RIHD [138, 169]. Since the miR expression profile can be tissue-specific, the circulating miR profile may reflect the severity of radiation damage and correlate with the risk for the development of late organ-specific complications after RT. A clinical study enrolling breast cancer patients demonstrated the association between the circulating levels of the atherosclerosisassociated miR-146a, miR-155, miR-221, and miR-222 and later development of RT-induced cardiovascular complications [170]. Another clinical study found in non-small cell lung cancer NSCLC patients that the decrease of circulating miR-29a-3p and miR-150-5p levels was correlated with the RT dose delivered to the chest [171].

\section{Conclusions and perspectives}

Much has been learned about the pathomechanism and clinical significance of RIHD in the past decades. All forms of radiation heart damage are dose-dependent and volumedependent progressive alterations that should be prevented or, if manifest, should be early diagnosed and effectively treated to prevent definitive deterioration or fatal outcome. The key-event is cellular damage that results in cell loss and initiates inflammation and fibrosis, which may affect any of the structures of the heart. Although experimental in vitro 
and in vivo models have been used to study the pathophysiology of RIHD, the exact molecular mechanisms in the development of acute and chronic phases and the crosstalk between them are still not entirely clear. Future in vivo models that would better reflect clinical situations such as the presence of cardiovascular comorbidities or cancer, the modulatory effects of multimodality cancer therapy, and sexbased differences are much-needed. At present, there are no specific drugs approved for the prevention or treatment of RIHD. To lessen the burden that RT may cause to patients needing chest irradiation, the consideration and control of radiation dose to normal tissues and the use of individually selected RT techniques is essential. Obviously, prospective clinical trials are needed for the identification of novel predictors of radiation heart damage, new models, and new guidelines for optimal heart sparing. Future developments in cardiac-specific drugs or selective administration techniques, as well as personalized therapeutic approaches, are also essential for effectively reduce cardiovascular adverse effects following thoracic RT. Tailored monitoring of radiation heart sequelae based on individual risk-status within the frame of multidisciplinary onco-cardiology teamwork would enhance early intervention if needed.

Author contributions TC and MS conceptualized the manuscript. MS, ZV, RG, GS, ZZAK, MGK, and ZK searched the literature. MS, ZV, RG, GS, and ZK drafted the manuscript. ZZAK and MGK prepared Tables, MS prepared Figures. MS, LD, ZK, and TC edited and critically revised the manuscript.

Funding Open Access funding provided by University of Szeged. The work and publication were supported by the projects GINOP-2.3.2-152016-00040, NKFIH FK129094, EFOP-3.6.2-16-2017-00006 (LIVE LONGER) and by the Ministry of Human Capacities (20391-3/2018/ FEKUSTRAT). MS, RG, MGK, and ZZAK were supported by the New National Excellence Program of the Ministry of Human Capacities (ÚNKP-20-5-SZTE-166, ÚNKP-20-4-SZTE-150, UNKP-19-4-ISZTE-89, and UNKP-19-3-SZTE-159, UNKP-19-3-SZTE-160). MS is supported by the János Bolyai Research Fellowship of the Hungarian Academy of Sciences. MGK and ZZAK were supported by the EFOP 3.6.3-VEKOP-16-2017-00009.

\section{Compliance with ethical standards}

\section{Conflict of interest None.}

Open Access This article is licensed under a Creative Commons Attribution 4.0 International License, which permits use, sharing, adaptation, distribution and reproduction in any medium or format, as long as you give appropriate credit to the original author(s) and the source, provide a link to the Creative Commons licence, and indicate if changes were made. The images or other third party material in this article are included in the article's Creative Commons licence, unless indicated otherwise in a credit line to the material. If material is not included in the article's Creative Commons licence and your intended use is not permitted by statutory regulation or exceeds the permitted use, you will need to obtain permission directly from the copyright holder. To view a copy of this licence, visit http://creativecommons.org/licenses/by/4.0/.

\section{References}

1. WHO. Cardiovascular Diseases (CVDs) (2017). Available from: http://www.who.int/mediacentre/factsheets/fs317/en/

2. WHO. Cancer (2018). Available from: https://www.who.int/ news-room/fact-sheets/detail/cancer

3. Sarfati D, Koczwara B, Jackson C (2016) The impact of comorbidity on cancer and its treatment. CA Cancer J Clin 66:337-350. https://doi.org/10.3322/caac. 21342

4. Menezes KM, Wang H, Hada M, Saganti PB (2018) Radiation matters of the heart: a mini review. Front Cardiovasc Med. https ://doi.org/10.3389/fcvm.2018.00083

5. Stewart FA, Seemann I, Hoving S, Russell NS (2013) Understanding radiation-induced cardiovascular damage and strategies for intervention. Clin Oncol 25:617-624. https://doi. org/10.1016/j.clon.2013.06.012

6. Taylor C, Correa C, Duane FK, Aznar MC, Anderson SJ, Bergh J, Dodwell D, Ewertz M, Gray R, Jagsi R, Pierce L, Pritchard KI, Swain S, Wang Z, Wang Y, Whelan T, Peto R, McGale P, Early Breast Cancer Trialists' Collaborative Group (2017) Estimating the Risks of Breast Cancer Radiotherapy: Evidence From Modern Radiation Doses to the Lungs and Heart and From Previous Randomized Trials. J Clin Oncol 35:16411649. https://doi.org/10.1200/JCO.2016.72.0722

7. Andratschke N, Maurer J, Molls M, Trott K-R (2011) Late radiation-induced heart disease after radiotherapy. Clinical importance, radiobiological mechanisms and strategies of prevention. Radiother Oncol 100:160-166. https://doi.org/10.1016/j. radonc.2010.08.010

8. Darby SC, Ewertz M, McGale P, Bennet AM, Blom-Goldman U, Brønnum D, Correa C, Cutter D, Gagliardi G, Gigante B, Jensen M-B, Nisbet A, Peto R, Rahimi K, Taylor C, Hall P (2013) Risk of ischemic heart disease in women after radiotherapy for breast cancer. N Engl J Med 368:987-998. https:// doi.org/10.1056/NEJMoa1209825

9. van Nimwegen FA, Schaapveld M, Cutter DJ, Janus CPM, Krol ADG, Hauptmann M, Kooijman K, Roesink J, van der Maazen R, Darby SC, Aleman BMP, van Leeuwen FE (2016) Radiation dose-response relationship for risk of coronary heart disease in survivors of hodgkin lymphoma. J Clin Oncol 34:235-243. https://doi.org/10.1200/JCO.2015.63.4444

10. Hancock SL, Donaldson SS, Hoppe RT (1993) Cardiac disease following treatment of hodgkin's disease in children and adolescents. J Clin Oncol 11:1208-1215. https://doi.org/10.1200/ JCO.1993.11.7.1208

11. Darby SC, McGale P, Taylor CW, Peto R (2005) Long-term mortality from heart disease and lung cancer after radiotherapy for early breast cancer: prospective cohort study of about 300,000 women in US SEER cancer registries. Lancet Oncol 6:557-565. https://doi.org/10.1016/S1470-2045(05)70251-5

12. Rassaf T, Totzeck M, Backs J, Bokemeyer C, Hallek M, Hilfiker-Kleiner D, Hochhaus A, Lüftner D, Müller OJ, Neudorf U, Pfister R, von Haehling S, Lehmann LH, Bauersachs J, Committee for Clinical Cardiovascular Medicine of the German Cardiac Society (2020) Onco-Cardiology: Consensus paper of the german cardiac society, the German society for pediatric cardiology and congenital heart defects and the German society for hematology and medical oncology. Clin Res Cardiol 109:1197-1222. https://doi.org/10.1007/s00392-02001636-7

13. Zamorano JL, Lancellotti P, Rodriguez Muñoz D, Aboyans V, Asteggiano R, Galderisi M, Habib G, Lenihan DJ, Lip GYH, Lyon AR, Lopez Fernandez T, Mohty D, Piepoli MF, Tamargo J, Torbicki A, Suter TM, ESC Scientific Document Group (2016) 2016 ESC position paper on cancer treatments and cardiovascular 
toxicity developed under the auspices of The ESC committee for practice guidelines: the task force for cancer treatments and cardiovascular toxicity of the european society of cardiology (ESC). Eur Heart J 37:2768-2801. https://doi.org/10.1093/eurheartj/ ehw211

14. Wang H, Wei J, Zheng Q, Meng L, Xin Y, Yin X, Jiang X (2019) Radiation-induced heart disease: a review of classification, mechanism and prevention. Int J Biol Sci 15:2128-2138. https ://doi.org/10.7150/ijbs.35460

15. Jacobse JN, Duane FK, Boekel NB, Schaapveld M, Hauptmann M, Hooning MJ, Seynaeve CM, Baaijens MHA, Gietema JA, Darby SC, van Leeuwen FE, Aleman BMP, Taylor CW (2019) Radiation dose-response for risk of myocardial infarction in breast cancer survivors. Int J Radiat Oncol Biol Phys 103:595604. https://doi.org/10.1016/j.ijrobp.2018.10.025

16. Boekel NB, Jacobse JN, Schaapveld M, Hooning MJ, Gietema JA, Duane FK, Taylor CW, Darby SC, Hauptmann M, Seynaeve CM, Baaijens MHA, Sonke GS, Rutgers EJT, Russell NS, Aleman BMP, van Leeuwen FE (2018) Cardiovascular disease incidence after internal mammary chain irradiation and anthracycline-based chemotherapy for breast cancer. Br J Cancer 119:408-418. https://doi.org/10.1038/s41416-018-0159-x

17. Demirci S, Nam J, Hubbs JL, Nguyen T, Marks LB (2009) Radiation-induced cardiac toxicity after therapy for breast cancer: interaction between treatment Era and follow-up duration. Int $\mathbf{J}$ Radiat Oncol Biol Phys 73:980-987. https://doi.org/10.1016/j. ijrobp.2008.11.016

18. Rehammar JC, Jensen M-B, McGale P, Lorenzen EL, Taylor C, Darby SC, Videbæk L, Wang Z, Ewertz M (2017) Risk of heart disease in relation to radiotherapy and chemotherapy with anthracyclines among 19,464 breast cancer patients in Denmark, 19772005. Radiother Oncol 123:299-305. https://doi.org/10.1016/j. radonc.2017.03.012

19. Yavas G, Gultekin M, Yildiz O, Seyrek M, Demirkol S, Toy H, Sargon M, Ozkayar O, Uner A, Yildiz F, Akyol F (2017) Assessment Of concomitant versus sequential trastuzumab on radiation-induced cardiovascular toxicity. Hum Exp Toxicol 36:1121-1130. https://doi.org/10.1177/0960327116680276

20. Cuomo JR, Sharma GK, Conger PD, Weintraub NL (2016) Novel concepts in radiation-induced cardiovascular disease. World $\mathrm{J}$ Cardiol 8:504-519. https://doi.org/10.4330/wjc.v8.i9.504

21. Chang H-M, Okwuosa TM, Scarabelli T, Moudgil R, Yeh ETH (2017) Cardiovascular complications of cancer therapy: best practices in diagnosis, prevention, and management: Part 2. J Am Coll Cardiol 70:2552-2565. https://doi.org/10.1016/j. jacc.2017.09.1095

22. Bertog SC, Thambidorai SK, Parakh K, Schoenhagen P, Ozduran V, Houghtaling PL, Lytle BW, Blackstone EH, Lauer MS, Klein AL (2004) Constrictive pericarditis: etiology and cause-specific survival after pericardiectomy. J Am Coll Cardiol 43:1445-1452. https://doi.org/10.1016/j.jacc.2003.11.048

23. Dutta SW, Aliotta E, Alonso CE, Bliley RC, Romano KD, Libby B, Showalter TN, Showalter SL, Janowski EM (2020) Normal tissue dose and risk estimates from whole and partial breast radiation techniques. Breast J 26:1308-1315. https://doi.org/10.1111/ tbj. 13735

24. Lancellotti P, Anker SD, Donal E, Edvardsen T, Popescu BA, Farmakis D, Filippatos G, Habib G, Maggioni AP, Jerusalem G, Galderisi M (2015) EACVI/HFA cardiac oncology toxicity registry in breast cancer patients: rationale, study design, and methodology (EACVI/HFA COT Registry)—Eurobservational research program of the european society of cardiology. Eur Heart J Cardiovasc Imaging 16:466-470. https://doi.org/10.1093/ ehjci/jev024

25. Wang W, Wainstein R, Freixa X, Dzavik V, Fyles A (2011) Quantitative coronary angiography findings of patients who received previous breast radiotherapy. Radiother Oncol 100:184-188. https://doi.org/10.1016/j.radonc.2011.03.009

26. Sio TT, Liang JJ, Chang K, Jayakrishnan R, Novotny PJ, Prasad A, Miller RC (2017) Dosimetric correlate of cardiac-specific survival among patients undergoing coronary artery stenting after thoracic radiotherapy for cancer. Am J Clin Oncol 40:133-139. https://doi.org/10.1097/COC.0000000000000135

27. van den Bogaard VAB, Ta BDP, van der Schaaf A, Bouma $\mathrm{AB}$, Middag AMH, Bantema-Joppe EJ, van Dijk LV, van Dijk-Peters FBJ, Marteijn LAW, de Bock GH, Burgerhof JGM, Gietema JA, Langendijk JA, Maduro JH, Crijns APG (2017) Validation and modification of a prediction model for acute cardiac events in patients with breast cancer treated with radiotherapy based on three-dimensional dose distributions to cardiac substructures. J Clin Oncol 35:1171-1178. https://doi. org/10.1200/JCO.2016.69.8480

28. McGale P, Darby SC, Hall P, Adolfsson J, Bengtsson N-O, Bennet AM, Fornander T, Gigante B, Jensen M-B, Peto R, Rahimi K, Taylor CW, Ewertz M (2011) Incidence of heart disease in 35,000 women treated with radiotherapy for breast cancer in Denmark and Sweden. Radiother Oncol 100:167175. https://doi.org/10.1016/j.radonc.2011.06.016

29. Hardy D, Liu C-C, Cormier JN, Xia R, Du XL (2010) Cardiac toxicity in association with chemotherapy and radiation therapy in a large cohort of older patients with non-small-cell lung cancer. Ann Oncol 21:1825-1833. https://doi.org/10.1093/ annonc/mdq042

30. Taylor C, McGale P, Brønnum D, Correa C, Cutter D, Duane FK, Gigante B, Jensen M-B, Lorenzen E, Rahimi K, Wang Z, Darby SC, Hall P, Ewertz M (2018) Cardiac structure injury after radiotherapy for breast cancer: cross-sectional study with individual patient data. J Clin Oncol 36:2288-2296. https://doi. org/10.1200/JCO.2017.77.6351

31. O'Donnell L, O'Neill T, Toner M, O'Briain S, Graham I (1986) Myocardial hypertrophy, fibrosis and infarction following exposure of the heart to radiation for hodgkin's disease. Postgrad Med J 62:1055-1058. https://doi.org/10.1136/ pgmj.62.733.1055

32. Monceau V, Meziani L, Strup-Perrot C, Morel E, Schmidt M, Haagen J, Escoubet B, Dörr W, Vozenin M-C (2013) Enhanced sensitivity to low dose irradiation of ApoE-/- mice mediated by early pro-inflammatory profile and delayed activation of the TGF $\beta 1$ cascade involved in fibrogenesis. PLoS ONE 8:e57052. https://doi.org/10.1371/journal.pone.0057052

33. Saiki H, Moulay G, Guenzel AJ, Liu W, Decklever TD, Classic KL, Pham L, Chen HH, Burnett JC, Russell SJ, Redfield MM (2017) Experimental cardiac radiation exposure induces ventricular diastolic dysfunction with preserved ejection fraction. Am J Physiol Heart Circul Physiol 313:H392-H407. https:// doi.org/10.1152/ajpheart.00124.2017

34. Sárközy M, Gáspár R, Zvara Á, Kiscsatári L, Varga Z, Kővári B, Kovács MG, Szúcs G, Fábián G, Diószegi P, Cserni G, Puskás LG, Thum T, Kahán Z, Csont T, Bátkai S (2019) Selective heart irradiation induces cardiac overexpression of the pro-hypertrophic miR-212. Front Oncol. 9:598. https://doi. org/10.3389/fonc.2019.00598

35. Tapio S (2016) Pathology and biology of radiation-induced cardiac disease. J Radiat Res 57:439-448. https://doi.org/10.1093/ jrr/rrw064

36. Cutter DJ, Schaapveld M, Darby SC, Hauptmann M, van Nimwegen FA, Krol ADG, Janus CPM, van Leeuwen FE, Aleman BMP (2015) Risk of valvular heart disease after treatment for hodgkin lymphoma. J Natl Cancer Inst. https://doi.org/10.1093/ jnci/djv008 
37. Lee MS, Finch W, Mahmud E (2013) Cardiovascular complications of radiotherapy. Am J Cardiol 112:1688-1696. https:// doi.org/10.1016/j.amjcard.2013.07.031

38. Adams MJ, Lipshultz SE, Schwartz C, Fajardo LF, Coen V, Constine LS (2003) Radiation-associated cardiovascular disease: manifestations and management. Seminars Radiat Oncol 13:346-356. https://doi.org/10.1016/S1053-4296(03)00026-2

39. Heidenreich PA, Hancock SL, Lee BK, Mariscal CS, Schnittger I (2003) Asymptomatic cardiac disease following mediastinal irradiation. J Am Coll Cardiol 42:743-749. https://doi. org/10.1016/S0735-1097(03)00759-9

40. Jaworski C, Mariani JA, Wheeler G, Kaye DM (2013) Cardiac complications of thoracic irradiation. J Am Coll Cardiol 61:2319-2328. https://doi.org/10.1016/j.jacc.2013.01.090

41. Armanious MA, Mishra S, Fradley MG (2018) Electrophysiologic toxicity of chemoradiation. Curr Oncol Rep 20:45. https ://doi.org/10.1007/s11912-018-0691-0

42. de Waard DE, Verhorst PM, Visser CA (1996) Exercise-induced syncope as late consequence of radiotherapy. Int J Cardiol 57:289-291. https://doi.org/10.1016/s0167-5273(96)02835-5

43. Taunk NK, Haffty BG, Kostis JB, Goyal S (2015) Radiationinduced heart disease: pathologic abnormalities and putative mechanisms. Front Oncol. https://doi.org/10.3389/ fonc.2015.00039

44. Slezak J, Kura B, Babal P, Barancik M, Ferko M, Frimmel K, Kalocayova B, Kukreja RC, Lazou A, Mezesova L, Okruhlicova L, Ravingerova T, Singal PK, Szeiffova Bacova B, Viczenczova C, Vrbjar N, Tribulova N (2017) Potential markers and metabolic processes involved in the mechanism of radiation-induced heart injury. Can J Physiol Pharmacol 95:1190-1203. https://doi. org/10.1139/cjpp-2017-0121

45. Schultz-Hector S (1992) Radiation-induced heart disease: review of experimental data on dose response and pathogenesis. Int $\mathbf{J}$ Radiat Biol 61:149-160. https://doi.org/10.1080/0955300921 4550761

46. Slama MS, Le Guludec D, Sebag C, Leenhardt AR, Davy JM, Pellerin DE, Drieu LH, Victor J, Brechenmacher C, Motté G (1991) Complete atrioventricular block following mediastinal irradiation: a report of six cases. Pacing Clin Electrophysiol 14:1112-1118. https://doi.org/10.1111/j.1540-8159.1991.tb028 42.x

47. Orzan F, Brusca A, Gaita F, Giustetto C, Figliomeni MC, Libero L (1993) Associated cardiac lesions in patients with radiationinduced complete heart block. Int J Cardiol 39:151-156. https:// doi.org/10.1016/0167-5273(93)90027-e

48. Azzam EI, Jay-Gerin J-P, Pain D (2012) Ionizing radiationinduced metabolic oxidative stress and prolonged cell injury. Cancer Lett 327:48-60. https://doi.org/10.1016/j.canle t.2011.12.012

49. Spitz DR, Azzam EI, Jian Li J, Gius D (2004) Metabolic oxidation/reduction reactions and cellular responses to ionizing radiation: a unifying concept in stress response biology. Cancer Metastasis Rev 23:311-322. https://doi.org/10.1023/B:CANC.00000 31769.14728.bc

50. Mikkelsen RB, Wardman P (2003) Biological chemistry of reactive oxygen and nitrogen and radiation-induced signal transduction mechanisms. Oncogene 22:5734-5754. https://doi. org/10.1038/sj.onc. 1206663

51. Kim W, Lee S, Seo D, Kim D, Kim K, Kim E, Kang J, Seong KM, Youn H, Youn B (2019) Cellular stress responses in radiotherapy. Cells. https://doi.org/10.3390/cells8091105

52. Halle M, Hall P, Tornvall P (2011) Cardiovascular disease associated with radiotherapy: activation of nuclear factor kappa-B. J Intern Med 269:469-477. https://doi.org/10.111 $1 /$ j.1365-2796.2011.02353.x
53. Chou C-H, Chen S-U, Cheng JC-H (2009) Radiation-induced interleukin-6 expression through MAPK/P38/NF-kappab signaling pathway and the resultant antiapoptotic effect on endothelial cells through Mcl-1 expression with Sil6-ralpha. Int J Radiat Oncol Biol Phys 75:1553-1561. https://doi.org/10.1016/j.ijrob p.2009.08.034

54. Hallahan D, Kuchibhotla J, Wyble C (1996) Cell adhesion molecules mediate radiation-induced leukocyte adhesion to the vascular endothelium. Cancer Res 56:5150-5155

55. Wondergem J, Wedekind LE, Bart CI, Chin A, van der Laarse A, Beekhuizen H (2004) Irradiation of mechanically-injured human arterial endothelial cells leads to increased gene expression and secretion of inflammatory and growth promoting cytokines. Atherosclerosis 175:59-67. https://doi.org/10.1016/j.atherosclerosis .2004 .02 .018

56. Meeren AV, Bertho JM, Vandamme M, Gaugler MH (1997) Ionizing radiation enhances IL- 6 and IL- 8 production by human endothelial cells. Mediators Inflamm 6:185-193. https://doi. org/10.1080/09629359791677

57. Boerma M, Schutte-Bart CI, Wedekind LE, Beekhuizen H, Wondergem $J$ (2003) Effects of multiple doses of ionizing radiation on cytokine expression in rat and human cells. Int J Radiat Biol 79:889-896. https://doi.org/10.1080/09553000310001626117

58. Yarnold J, Brotons M-CV (2010) Pathogenetic mechanisms in radiation fibrosis. Radiother Oncol 97:149-161. https://doi. org/10.1016/j.radonc.2010.09.002

59. Mathias D, Mitchel REJ, Barclay M, Wyatt H, Bugden M, Priest ND, Whitman SC, Scholz M, Hildebrandt G, Kamprad M, Glasow A (2015) Low-dose irradiation affects expression of inflammatory markers in the heart of apoe -/- mice. PLoS ONE 10:e0119661. https://doi.org/10.1371/journal.pone.0119661

60. Chen Z-Y, Hu Y-Y, Hu X-F, Cheng L-X (2018) The conditioned medium of human mesenchymal stromal cells reduces irradiation-induced damage in cardiac fibroblast cells. J Radiat Res 59:555-564. https://doi.org/10.1093/jrr/rry048

61. Gao S, Zhao Z, Wu R, Zeng Y, Zhang Z, Miao J, Yuan Z (2017) Bone marrow mesenchymal stem cell transplantation improves radiation-induced heart injury through DNA damage repair in rat model. Radiat Environ Biophys 56:63-77. https://doi. org/10.1007/s00411-016-0675-0

62. Christersdottir T, Pirault J, Gisterå A, Bergman O, Gallina AL, Baumgartner R, Lundberg AM, Eriksson P, Yan Z-Q, PaulssonBerne G, Hansson GK, Olofsson PS, Halle M (2019) Prevention of radiotherapy-induced arterial inflammation by interleukin-1 blockade. Eur Heart J 40:2495-2503. https://doi.org/10.1093/ eurheartj/ehz206

63. Gao M, Shirato H, Miyasaka K, Kuwabara M, Koyama T (2000) Induction of growth factors in rat cardiac tissue by $\mathrm{X}$ irradiation. Radiat Res 153:540-547. https://doi.org/10.1667/00337587(2000)153[0540:iogfir]2.0.co;2

64. Boerma M, Bart CI, Wondergem J (2002) Effects of ionizing radiation on gene expression in cultured rat heart cells. Int $\mathrm{J}$ Radiat Biol 78:219-225. https://doi.org/10.1080/0955300011 0094797

65. Sievert W, Trott K-R, Azimzadeh O, Tapio S, Zitzelsberger H, Multhoff G (2015) Late proliferating and inflammatory effects on murine microvascular heart and lung endothelial cells after irradiation. Radiother Oncol 117:376-381. https://doi.org/10.1016/j. radonc.2015.07.029

66. Okamoto T, Akaike T, Nagano T, Miyajima S, Suga M, Ando M, Ichimori K, Maeda H (1997) Activation of human neutrophil procollagenase by nitrogen dioxide and peroxynitrite: a novel mechanism for procollagenase activation involving nitric oxide. Arch Biochem Biophys 342:261-274. https://doi.org/10.1006/ abbi.1997.0127 
67. Mountain DJH, Singh M, Menon B, Singh K (2007) Interleukin1 beta increases expression and activity of matrix metalloproteinase-2 in cardiac microvascular endothelial cells: role of Pkcalpha/Beta1 and Mapks. Am J Physiol Cell Physiol 292:C867-875. https://doi.org/10.1152/ajpcell.00161.2006

68. Chow AK, Cena J, Schulz R (2007) Acute actions and novel targets of matrix metalloproteinases in the heart and vasculature. $\mathrm{Br}$ J Pharmacol 152:189-205. https://doi.org/10.1038/sj.bjp.07073 44

69. Csont T, Viappiani S, Sawicka J, Slee S, Altarejos JY, BatinićHaberle I, Schulz R (2005) The involvement of superoxide and iNOS-derived NO in cardiac dysfunction induced by pro-inflammatory cytokines. J Mol Cell Cardiol 39:833-840. https://doi. org/10.1016/j.yjmcc.2005.07.010

70. Pathak R, Shao L, Ghosh SP, Zhou D, Boerma M, Weiler H, Hauer-Jensen M (2015) Thrombomodulin contributes to gamma tocotrienol-mediated lethality protection and hematopoietic cell recovery in irradiated mice. PLoS ONE 10:e0122511. https://doi. org/10.1371/journal.pone.0122511

71. Danckwardt S, Hentze MW, Kulozik AE (2013) Pathologies at the nexus of blood coagulation and inflammation: thrombin in hemostasis, cancer, and beyond. J Mol Med 91:1257-1271. https ://doi.org/10.1007/s00109-013-1074-5

72. Kim W, Son B, Lee S, Do H, Youn B (2018) Targeting the Enzymes involved in arachidonic acid metabolism to improve radiotherapy. Cancer Metastasis Rev 37:213-225. https://doi. org/10.1007/s10555-018-9742-0

73. Ramirez MU, Hernandez SR, Soto-Pantoja DR, Cook KL (2019) Endoplasmic reticulum stress pathway, the unfolded protein response, modulates immune function in the tumor microenvironment to impact tumor progression and therapeutic response. Int J Mol Sci. https://doi.org/10.3390/ijms21010169

74. Dandekar A, Mendez R, Zhang K (2015) Cross talk between er stress, oxidative stress, and inflammation in health and disease. Methods Mol Biol 1292:205-214. https://doi. org/10.1007/978-1-4939-2522-3_15

75. Livingston K, Schlaak RA, Puckett LL, Bergom C (2020) The role of mitochondrial dysfunction in radiation-induced heart disease: from bench to bedside. Front Cardiovasc Med. https://doi. org/10.3389/fcvm.2020.00020

76. Salata C, Ferreira-Machado SC, De Andrade CBV, Mencalha AL, Mandarim-De-Lacerda CA, de Almeida CE (2014) Apoptosis induction of cardiomyocytes and subsequent fibrosis after irradiation and neoadjuvant chemotherapy. Int J Radiat Biol 90:284-290. https://doi.org/10.3109/09553002.2014.887869

77. Zhu H, Sun A (2018) Programmed necrosis in heart disease: molecular mechanisms and clinical implications. J Mol Cell Cardiol 116:125-134. https://doi.org/10.1016/j.yjmcc.2018.01.018

78. Huang S, Che J, Chu Q, Zhang P (2020) The role of NLRP3 inflammasome in radiation-induced cardiovascular injury. Front Cell Dev Biol. https://doi.org/10.3389/fcell.2020.00140

79. Wei J, Wang H, Wang H, Wang B, Meng L, Xin Y, Jiang X (2019) The role of NLRP3 inflammasome activation in radiation damage. Biomed Pharmacother 118:109217. https://doi. org/10.1016/j.biopha.2019.109217

80. Nikoletopoulou V, Markaki M, Palikaras K, Tavernarakis N (2013) Crosstalk between apoptosis, necrosis and autophagy. Biochim Biophys Acta 1833:3448-3459. https://doi. org/10.1016/j.bbamcr.2013.06.001

81. Hu L, Wang H, Huang L, Zhao Y, Wang J (2016) Crosstalk between autophagy and intracellular radiation response (Review). Int J Oncol 49:2217-2226. https://doi.org/10.3892/ijo.2016.3719

82. Tam SY, Wu VWC, Law HKW (2017) Influence of autophagy on the efficacy of radiotherapy. Radiat Oncol. https://doi. org/10.1186/s13014-017-0795-y
83. Pacher P, Szabo C (2008) Role of The peroxynitrite-poly(adpribose) polymerase pathway in human disease. Am J Pathol 173:2-13. https://doi.org/10.2353/ajpath.2008.080019

84. Csonka C, Sárközy M, Pipicz M, Dux L, Csont T (2016) Modulation of hypercholesterolemia-induced oxidative/nitrative stress in the heart. Oxid Med Cell Longev. https://doi. org/10.1155/2016/3863726

85. Sárközy M, Kovács ZZA, Kovács MG, Gáspár R, Szúcs G, Dux L (2018) Mechanisms and modulation of oxidative/nitrative stress in Type 4 cardio-renal syndrome and renal sarcopenia. Front Physiol. 9:1648. https://doi.org/10.3389/fphys.2018.01648

86. Prathumsap N, Shinlapawittayatorn K, Chattipakorn SC, Chattipakorn N (2020) Effects of doxorubicin on the heart: from molecular mechanisms to intervention strategies. Eur J Pharmacol 866:172818 https://doi.org/10.1016/j.ejphar.2019.172818

87. Boerma M, Sridharan V, Mao X-W, Nelson GA, Cheema AK, Koturbash I, Singh SP, Tackett AJ, Hauer-Jensen M (2016) Effects of ionizing radiation on the heart. Mutat Res 770:319327. https://doi.org/10.1016/j.mrrev.2016.07.003

88. Bleeke T, Zhang H, Madamanchi N, Patterson C, Faber JE (2004) Catecholamine-induced vascular wall growth is dependent on generation of reactive oxygen species. Circ Res 94:37-45. https ://doi.org/10.1161/01.RES.0000109412.80157.7D

89. Wassmann S, Stumpf M, Strehlow K, Schmid A, Schieffer B, Böhm M, Nickenig G (2004) Interleukin-6 induces oxidative stress and endothelial dysfunction by overexpression of the angiotensin II type 1 receptor. Circ Res 94:534-541. https://doi. org/10.1161/01.RES.0000115557.25127.8D

90. Schultz JEJ, Witt SA, Glascock BJ, Nieman ML, Reiser PJ, Nix SL, Kimball TR, Doetschman T (2002) TGF-B1 mediates the hypertrophic cardiomyocyte growth induced by angiotensin II. J Clin Invest 109:787-796. https://doi.org/10.1172/JCI14190

91. Zhang W, Wang W, Yu H, Zhang Y, Dai Y, Ning C, Tao L, Sun H, Kellems RE, Blackburn MR, Xia Y (2012) Interleukin 6 underlies angiotensin ii-induced hypertension and chronic renal damage. Hypertension 59:136-144. https://doi.org/10.1161/ HYPERTENSIONAHA.111.173328

92. Kiscsatári L, Sárközy M, Kővári B, Varga Z, Gömöri K, Morvay N, Leprán I, Hegyesi H, Fábián G, Cserni B, Cserni G, Csont T, Kahán Z (2016) High-dose radiation induced heart damage in a rat model. In Vivo 30:623-631

93. Boerma M, Roberto KA, Hauer-Jensen M (2008) Prevention and treatment of functional and structural radiation injury in the rat heart by pentoxifylline and alpha-tocopherol. Int J Radiat Oncol Biol Phys 72:170-177. https://doi.org/10.1016/j.ijrob p.2008.04.042

94. Ejaz A, Greenberger JS, Rubin PJ (2019) Understanding the mechanism of radiation induced fibrosis and therapy options. Pharmacol Ther 204:107399. https://doi.org/10.1016/j.pharm thera.2019.107399

95. Rockey DC, Bell PD, Hill JA (2015) Fibrosis-a common pathway to organ injury and failure. N Engl J Med 373:96. https://doi. org/10.1056/NEJMc1504848

96. Shimizu I, Minamino T (2019) Cellular senescence in cardiac diseases. J Cardiol 74:313-319. https://doi.org/10.1016/j. jjcc.2019.05.002

97. Wang Y, Boerma M, Zhou D (2016) Ionizing radiation-induced endothelial cell senescence and cardiovascular diseases. Radiat Res 186:153-161. https://doi.org/10.1667/RR14445.1

98. Gkantaifi A, Papadopoulos C, Spyropoulou D, Toumpourleka M, Iliadis G, Kardamakis D, Nikolaou M, Tsoukalas N, Kyrgias G, Tolia M (2019) Breast radiotherapy and early adverse cardiac effects. the role of serum biomarkers and strain echocardiography. Anticancer Res 39:1667-1673. https://doi.org/10.21873 /anticanres. 13272 
99. Lipshultz SE, Adams MJ, Colan SD, Constine LS, Herman EH, Hsu DT, Hudson MM, Kremer LC, Landy DC, Miller TL, Oeffinger KC, Rosenthal DN, Sable CA, Sallan SE, Singh GK, Steinberger J, Cochran TR, Wilkinson JD, American Heart Association Congenital Heart Defects Committee of the Council on Cardiovascular Disease in the Young, Council on Basic Cardiovascular Sciences, Council on Cardiovascular and Stroke Nursing, Council on Cardiovascular Radiolo (2013) Long-term cardiovascular toxicity in children, adolescents, and young adults who receive cancer therapy: pathophysiology, course, monitoring, management, prevention, and research directions: a scientific statement from the american heart association. Circulation 128:1927-1995. https://doi.org/10.1161/CIR.0b013e3182a8809 9

100. Nishimura RA, Otto CM, Bonow RO, Carabello BA, Erwin JP, Fleisher LA, Jneid H, Mack MJ, McLeod CJ, O'Gara PT, Rigolin VH, Sundt TM, Thompson A (2017) 2017 AHA/ACC focused update of the 2014 AHA/ACC guideline for the management of patients with valvular Heart disease: a report of the american college of cardiology/american Heart association task force on clinical practice guidelines. J Am Coll Cardiol 70:252-289. https://doi.org/10.1016/j.jacc.2017.03.011

101. Desai N, Currey A, Kelly T, Bergom C (2019) Nationwide trends in heart-sparing techniques utilized in radiation therapy for breast cancer. Adv Radiat Oncol 4:246-252. https://doi. org/10.1016/j.adro.2019.01.001

102. Taylor CW, Kirby AM (2015) Cardiac side-effects from breast cancer radiotherapy. Clin Oncol (R Coll Radiol) 27:621-629. https://doi.org/10.1016/j.clon.2015.06.007

103. Varga Z, Cserháti A, Rárosi F, Boda K, Gulyás G, Együd Z, Kahán Z (2014) Individualized positioning for maximum heart protection during breast irradiation. Acta Oncol 53:58-64. https://doi.org/10.3109/0284186X.2013.781674

104. Kahán Z, Rárosi F, Gaál S, Cserháti A, Boda K, Darázs B, Kószó R, Lakosi F, Gulybán Á, Coucke PA, Varga Z (2018) A simple clinical method for predicting the benefit of prone vs. supine positioning in reducing heart exposure during left breast radiotherapy. Radiother Oncol 126:487-492. https://doi. org/10.1016/j.radonc.2017.12.021

105. Rárosi F, Boda K, Kahán Z, Varga Z (2019) Decision curve analysis apropos of choice of preferable treatment positioning during breast irradiation. BMC Med Inform Decis Mak 19:204. https://doi.org/10.1186/s12911-019-0927-4

106. Desai MY, Windecker S, Lancellotti P, Bax JJ, Griffin BP, Cahlon O, Johnston DR (2019) Prevention, diagnosis, and management of radiation-associated cardiac disease: JACC scientific expert panel. J Am Coll Cardiol 74:905-927. https ://doi.org/10.1016/j.jacc.2019.07.006

107. Lai J, Hu S, Luo Y, Zheng R, Zhu Q, Chen P, Chi B, Zhang Y, Zhong F, Long X (2020) Meta-analysis of deep inspiration breath hold (dibh) versus free breathing (FB) in postoperative radiotherapy for left-side breast cancer. Breast Cancer 27:299_ 307. https://doi.org/10.1007/s12282-019-01023-9

108. Specht L, Dabaja B, Illidge T, Wilson LD, Hoppe RT, International Lymphoma Radiation Oncology Group (2015) Modern Radiation therapy for primary cutaneous lymphomas: field and dose guidelines from the international lymphoma radiation oncology group. Int J Radiat Oncol Biol Phys 92:32-39. https://doi.org/10.1016/j.ijrobp.2015.01.008

109. Nestle U, De Ruysscher D, Ricardi U, Geets X, Belderbos J, Pöttgen C, Dziadiuszko R, Peeters S, Lievens Y, Hurkmans C, Slotman B, Ramella S, Faivre-Finn C, McDonald F, Manapov F, Putora PM, LePéchoux C, Van Houtte P (2018) ESTRO ACROP guidelines for target volume definition in the treatment of locally advanced non-small cell lung cancer. Radiother Oncol 127:1-5. https://doi.org/10.1016/j.radonc.2018.02.023
110. Wu AJ, Bosch WR, Chang DT, Hong TS, Jabbour SK, Kleinberg LR, Mamon HJ, Thomas CR, Goodman KA (2015) Expert consensus contouring guidelines for intensity modulated radiation therapy in esophageal and gastroesophageal junction cancer. Int J Radiat Oncol Biol Phys 92:911-920. https://doi. org/10.1016/j.ijrobp.2015.03.030

111. Sridharan V, Tripathi P, Aykin-Burns N, Krager KJ, Sharma SK, Moros EG, Melnyk SB, Pavliv O, Hauer-Jensen M, Boerma M (2015) A Tocotrienol-enriched formulation protects against radiation-induced changes in cardiac mitochondria without modifying late cardiac function or structure. Radiat Rare 183:357-366. https://doi.org/10.1667/RR13915.1

112. Liu H, Xiong M, Xia Y-F, Cui N-J, Lu R-B, Deng L, Lin Y-H, Rong T-H (2009) Studies on pentoxifylline and tocopherol combination for radiation-induced heart disease in rats. Int J Radiat Oncol Biol Phys 73:1552-1559. https://doi. org/10.1016/j.ijrobp.2008.12.005

113. Sridharan V, Tripathi P, Sharma S, Corry PM, Moros EG, Singh A, Compadre CM, Hauer-Jensen M, Boerma M (2013) Effects of late administration of pentoxifylline and tocotrienols in an image-guided rat model of localized heart irradiation. PLoS ONE 8:e68762. https://doi.org/10.1371/journal.pone.0068762

114. Gurses I, Ozeren M, Serin M, Yucel N, Erkal HS (2018) Histopathological efficiency of amifostine in radiation-induced heart disease in rats. Bratisl Lek Listy 119:54-59. https://doi. org/10.4149/BLL_2018_011

115. Wasserman TH, Brizel DM (2001) The role of amifostine as a radioprotector. Oncology (Williston Park, NY) 15:1349-1354

116. Kouvaris JR, Kouloulias VE, Vlahos LJ (2007) Amifostine: the first selective-target and broad-spectrum radioprotector. Oncologist 12:738-747. https://doi.org/10.1634/theoncologist.12-6-738

117. Tokatli F, Uzal C, Doganay L, Kocak Z, Kaya M, Ture M, Kurum T, Alkaya F, Karadag H, Kutlu K (2004) The potential cardioprotective effects of amifostine in irradiated rats. Int J Radiat Oncol Biol Phys 58:1228-1234. https://doi.org/10.1016/j.ijrob p.2003.09.071

118. Kruse JJCM, Strootman EG, Wondergem J (2003) Effects of amifostine on radiation-induced cardiac damage. Acta Oncol 42:4-9. https://doi.org/10.1080/0891060310002168

119. Musa AE, Shabeeb D (2019) Radiation-induced heart diseases: protective effects of natural products. Medicina 55:126. https:// doi.org/10.3390/medicina55050126

120. O'Herron T, Lafferty J (2018) Prophylactic use of colchicine in preventing radiation induced coronary artery disease. Med Hypotheses 111:58-60. https://doi.org/10.1016/j. mehy.2017.12.021

121. Reeves WC, Stryker JA, Abt AB, Chung CK, Whitesell L, Zelis R (1980) Early corticosteroid administration in experimental radiation-induced heart disease. Radiology 134:533-535. https ://doi.org/10.1148/radiology.134.2.7352245

122. Reeves WC, Cunningham D, Schwiter EJ, Abt A, Skarlatos S, Wood MA, Whitesell L (1982) Myocardial hydroxyproline reduced by early administration of methylprednisolone or ibuprofen to rabbits with radiation-induced heart disease. Circulation 65:924-927. https://doi.org/10.1161/01.cir.65.5.924

123. Schjerning Olsen A-M, Fosbøl EL, Lindhardsen J, Folke F, Charlot M, Selmer C, Lamberts M, Bjerring Olesen J, Køber L, Hansen PR, Torp-Pedersen C, Gislason GH (2011) Duration of treatment with nonsteroidal anti-inflammatory drugs and impact an risk of death and recurrent myocardial infarction in patients with prior myocardial infarction: a nationwide cohort study. Circulation 123:2226-2235. https://doi.org/10.1161/CIRCULATIO NAHA.110.004671

124. Uehara Y, Murata Y, Shiga S, Hosoi Y (2016) NSAIDs Diclofenac, indomethacin, and meloxicam highly upregulate expression of ICAM-1 and COX-2 induced by X-irradiation 
in human endothelial cells. Biochem Biophys Res Commun 479:847-852. https://doi.org/10.1016/j.bbrc.2016.09.120

125. Salehifar E, Hosseinimehr SJ (2016) The use of cyclooxygenase-2 inhibitors for improvement of efficacy of radiotherapy in cancers. Drug Discov Today 21:654-662. https://doi. org/10.1016/j.drudis.2016.02.019

126. Kantor PF, Lucien A, Kozak R, Lopaschuk GD (2000) The Antianginal drug trimetazidine shifts cardiac energy metabolism from fatty acid oxidation to glucose oxidation by inhibiting mitochondrial long-chain 3-ketoacyl coenzyme a thiolase. Circ Res 86:580-588. https://doi.org/10.1161/01.res.86.5.580

127. Zhang J, He X, Bai X, Sun Y, Jiang P, Wang X, Li W, Zhang $Y$ (2020) Protective effect of trimetazidine in radiation-induced cardiac fibrosis in mice. J Radiat Res 61:657-665. https://doi. org/10.1093/jrr/rraa043

128. Granata R, Trovato L, Gallo MP, Destefanis S, Settanni F, Scarlatti F, Brero A, Ramella R, Volante M, Isgaard J, Levi R, Papotti M, Alloatti G, Ghigo E (2009) Growth hormone-releasing hormone promotes survival of cardiac myocytes in vitro and protects against ischaemia-reperfusion injury in rat heart. Cardiovasc Res 83:303-312. https://doi.org/10.1093/cvr/cvp090

129. Barabutis N, Siejka A, Schally AV (2011) Growth hormone releasing hormone induces the expression of nitric oxide synthase. J Cell Mol Med 15:1148-1155. https://doi.org/10.111 1/j.1582-4934.2010.01096.x

130. Cai R, Schally AV, Cui T, Szalontay L, Halmos G, Sha W, Kovacs M, Jaszberenyi M, He J, Rick FG, Popovics P, KanashiroTakeuchi R, Hare JM, Block NL, Zarandi M (2014) Synthesis of new potent agonistic analogs of growth hormone-releasing hormone (GHRH) and evaluation of their endocrine and cardiac activities. Peptides 52:104-112. https://doi.org/10.1016/j.pepti des.2013.12.010

131. Penna C, Settanni F, Tullio F, Trovato L, Pagliaro P, Alloatti G, Ghigo E, Granata R (2013) GH-releasing hormone induces cardioprotection in isolated male rat heart via activation of RISK and SAFE pathways. Endocrinology 154:1624-1635. https://doi. org/10.1210/en.2012-2064

132. Kanashiro-Takeuchi RM, Tziomalos K, Takeuchi LM, Treuer AV, Lamirault G, Dulce R, Hurtado M, Song Y, Block NL, Rick F, Klukovits A, Hu Q, Varga JL, Schally AV, Hare JM (2010) Cardioprotective effects of growth hormone-releasing hormone agonist after myocardial infarction. PNAS 107:2604-2609. https ://doi.org/10.1073/pnas.0914138107

133. Kanashiro-Takeuchi RM, Takeuchi LM, Rick FG, Dulce R, Treuer AV, Florea V, Rodrigues CO, Paulino EC, Hatzistergos KE, Selem SM, Gonzalez DR, Block NL, Schally AV, Hare JM (2012) Activation of growth hormone releasing hormone (GHRH) receptor stimulates cardiac reverse remodeling after myocardial infarction (MI). PNAS 109:559-563. https://doi. org/10.1073/pnas.1119203109

134. Kiscsatári L, Varga Z, Schally AV, Gáspár R, Nagy CT, Giricz Z, Ferdinandy P, Fábián G, Kahán Z, Görbe A (2016) Protection of neonatal rat cardiac myocytes against radiation-induced damage with agonists of growth hormone-releasing hormone. Pharmacol Res 111:859-866. https://doi.org/10.1016/j.phrs.2016.07.036

135. Lee M-S, Liu D-W, Hung S-K, Yu C-C, Chi C-L, Chiou W-Y, Chen L-C, Lin R-I, Huang L-W, Chew C-H, Hsu F-C, Chan MWY, Lin H-Y (2020) Emerging challenges of radiation-associated cardiovascular dysfunction (RACVD) in modern radiation oncology: clinical practice, bench investigation, and multidisciplinary care. Front Cardiovasc Med. https://doi.org/10.3389/ fcvm.2020.00016

136. Ichihara S, Noda A, Nagata $\mathrm{K}$, Obata $\mathrm{K}, \mathrm{Xu}$ J, Ichihara $\mathrm{G}$, Oikawa S, Kawanishi S, Yamada Y, Yokota M (2006) Pravastatin increases survival and suppresses an increase in myocardial matrix metalloproteinase activity in a rat model of heart failure.
Cardiovasc Res 69:726-735. https://doi.org/10.1016/j.cardi ores.2005.08.001

137. Kim JW, Rhee CK, Kim TJ, Kim YH, Lee SH, Yoon HK, Kim SC, Lee SY, Kwon SS, Kim KH, Kim YK (2010) Effect of pravastatin on bleomycin-induced acute lung injury and pulmonary fibrosis. Clin Exp Pharmacol Physiol 37:1055-1063. https ://doi.org/10.1111/j.1440-1681.2010.05431.x

138. Viczenczova C, Kura B, Egan Benova T, Yin C, Kukreja RC, Slezak J, Tribulova N, Szeiffova Bacova B (2018) Irradiationinduced cardiac connexin-43 and mir- 21 responses are hampered by treatment with atorvastatin and aspirin. Int J Mol Sci. https:// doi.org/10.3390/ijms19041128

139. Rousseau M, Gaugler M-H, Rodallec A, Bonnaud S, Paris F, Corre I (2011) RhoA GTPase regulates radiation-induced alterations in endothelial cell adhesion and migration. Biochem Biophys Res Commun 414:750-755. https://doi.org/10.1016/j. bbrc.2011.09.150

140. Cerda A, Rodrigues AC, Alves C, Genvigir FDV, Fajardo CM, Dorea EL, Gusukuma MC, Pinto GA, Hirata MH, Hirata RDC (2015) Modulation of adhesion molecules by cholesterollowering therapy in mononuclear cells from hypercholesterolemic patients. Cardiovasc Ther 33:168-176. https://doi. org/10.1111/1755-5922.12126

141. Ostrau C, Hülsenbeck J, Herzog M, Schad A, Torzewski M, Lackner KJ, Fritz G (2009) Lovastatin attenuates ionizing radiation-induced normal tissue damage in vivo. Radiother Oncol 92:492-499. https://doi.org/10.1016/j.radonc.2009.06.020

142. Zhang K, He X, Zhou Y, Gao L, Qi Z, Chen J, Gao X (2015) Atorvastatin ameliorates radiation-induced cardiac fibrosis in rats. Radiat Res 184:611-620. https://doi.org/10.1667/RR140 75.1

143. Wu R, Zeng Y (2009) Does angiotensin ii-aldosterone have a role in radiation-induced heart disease? Med Hypotheses 72:263-266. https://doi.org/10.1016/j.mehy.2008.09.051

144. van der Veen SJ, Ghobadi G, de Boer RA, Faber H, Cannon MV, Nagle PW, Brandenburg S, Langendijk JA, van Luijk P, Coppes RP (2015) ACE Inhibition attenuates radiation-induced cardiopulmonary damage. Radiother Oncol 114:96-103. https ://doi.org/10.1016/j.radonc.2014.11.017

145. Kma L, Gao F, Fish BL, Moulder JE, Jacobs ER, Medhora M (2012) Angiotensin converting enzyme inhibitors mitigate collagen synthesis induced by a single dose of radiation to the whole thorax. J Radiat Res 53:10-17. https://doi.org/10.1269/ jrr.11035

146. Gulati G, Heck SL, Ree AH, Hoffmann P, Schulz-Menger J, Fagerland MW, Gravdehaug B, von Knobelsdorff-Brenkenhoff F, Bratland A, Storås TH, Hagve T-A, Røsjø H, Steine K, Geisler J, Omland T (2016) Prevention of cardiac dysfunction during adjuvant breast Cancer therapy (PRADA): A $2 \times 2$ factorial, randomized, placebo-controlled, double-blind clinical trial of candesartan and metoprolol. Eur Heart J 37:1671-1680. https:// doi.org/10.1093/eurheartj/ehw022

147. Mendes-Ferreira P, De Keulenaer GW, Leite-Moreira AF, BrásSilva C (2013) Therapeutic potential of neuregulin-1 in cardiovascular disease. Drug Discov Today 18:836-842. https://doi. org/10.1016/j.drudis.2013.01.010

148. Galindo CL, Kasasbeh E, Murphy A, Ryzhov S, Lenihan S, Ahmad FA, Williams P, Nunnally A, Adcock J, Song Y, Harrell FE, Tran T-L, Parry TJ, Iaci J, Ganguly A, Feoktistov I, Stephenson MK, Caggiano AO, Sawyer DB, Cleator JH (2014) Anti-remodeling and anti-fibrotic effects of the neuregulin-1 $\beta$ glial growth factor 2 in a large animal model of heart failure. J Am Heart Assoc 3:e000773. https://doi.org/10.1161/ JAHA.113.000773

149. Vermeulen Z, Hervent A-S, Dugaucquier L, Vandekerckhove L, Rombouts M, Beyens M, Schrijvers DM, De Meyer GRY, 
Maudsley S, De Keulenaer GW, Segers VFM (2017) Inhibitory actions of the NRG-1/Erbb4 pathway in macrophages during tissue fibrosis in the heart, skin, and lung. Am J Physiol Heart Circ Physiol 313:H934-H945. https://doi.org/10.1152/ajpheart.00206 .2017

150. Pilz PM, Hamza O, Gidlöf O, Gonçalves IF, Tretter EV, Trojanek S, Abraham D, Heber S, Haller PM, Podesser BK, Kiss A (2019) Remote ischemic perconditioning attenuates adverse cardiac remodeling and preserves left ventricular function in a rat model of reperfused myocardial infarction. Int J Cardiol 285:72-79. https://doi.org/10.1016/j.ijcard.2019.03.003

151. Gu A, Jie Y, Sun L, Zhao S, You Q (2015) RhNRG-1 $\beta$ protects the myocardium against irradiation-induced damage via the ErbB2-ERK-SIRT1 Signaling Pathway. PLoS ONE 10:e0137337. https://doi.org/10.1371/journal.pone.0137337

152. Luu AZ, Chowdhury B, Al-Omran M, Teoh H, Hess DA, Verma $S$ (2018) Role of endothelium in doxorubicin-induced cardiomyopathy. JACC Basic Transl Sci 3:861-870. https://doi. org/10.1016/j.jacbts.2018.06.005

153. Kurokawa YK, Shang MR, Yin RT, George SC (2018) Modeling trastuzumab-related cardiotoxicity in vitro using human stem cell-derived cardiomyocytes. Toxicol Lett 285:74-80. https ://doi.org/10.1016/j.toxlet.2018.01.001

154. Chua Y, Ito Y, Pole J, Newman S, Chin S-F, Stein R, Ellis I, Caldas C, O'Hare M, Murrell A, Edwards P (2009) The NRG1 gene is frequently silenced by methylation in breast cancers and is a strong candidate for The $8 \mathrm{p}$ tumour suppressor gene. Oncogene 28:4041-4052. https://doi.org/10.1038/onc.2009.259

155. Tsai M-S, Shamon-Taylor LA, Mehmi I, Tang CK, Lupu R (2003) Blockage of heregulin expression inhibits tumorigenicity and metastasis of breast cancer. Oncogene 22:761-768. https ://doi.org/10.1038/sj.onc.1206130

156. Sharma UC, Sonkawade SD, Spernyak JA, Sexton S, Nguyen J, Dahal S, Attwood KM, Singh AK, van Berlo JH, Pokharel S (2018) A small peptide Ac-SDKP inhibits radiation-induced cardiomyopathy. Circ Heart Fail 11:e004867. https://doi. org/10.1161/CIRCHEARTFAILURE.117.004867

157. Hongmei P, Carretero OA, Brigstock DR, Nancy O-T, NourEddine R (2003) Ac-SDKP reverses cardiac fibrosis in rats with renovascular hypertension. Hypertension 42:1164-1170. https:// doi.org/10.1161/01.HYP.0000100423.24330.96

158. Sharma U, Rhaleb N-E, Pokharel S, Harding P, Rasoul S, Peng H, Carretero OA (2008) Novel anti-inflammatory mechanisms of N-Acetyl-Ser-Asp-Lys-Pro in hypertension-induced target organ damage. Am J Physiol Heart Circul Physiol 294:H1226-H1232. https://doi.org/10.1152/ajpheart.00305.2007

159. Li H, Cao L, Yi P-Q, Xu C, Su J, Chen P-Z, Li M, Chen J-Y (2019) Pituitary adenylate cyclase-activating polypeptide ameliorates radiation-induced cardiac injury. Am J Transl Res 11:6585-6599

160. Gasz B, Rácz B, Roth E, Borsiczky B, Ferencz A, Tamás A, Cserepes B, Lubics A, Gallyas F, Tóth G, Lengvári I, Reglodi D (2006) Pituitary adenylate cyclase activating polypeptide protects cardiomyocytes against oxidative stress-induced apoptosis. Peptides 27:87-94. https://doi.org/10.1016/j.peptides.2005.06.022

161. Bickelhaupt S, Erbel C, Timke C, Wirkner U, Dadrich M, Flechsig P, Tietz A, Pföhler J, Gross W, Peschke P, Hoeltgen L, Katus HA, Gröne H-J, Nicolay NH, Saffrich R, Debus J, Sternlicht MD, Seeley TW, Lipson KE, Huber PE (2017) Effects of CTGF blockade on attenuation and reversal of radiation-induced pulmonary fibrosis. J Natl Cancer Inst. https://doi.org/10.1093/jnci/djw339

162. Rabender C, Mezzaroma E, Mauro AG, Mullangi R, Abbate A, Anscher M, Hart B, Mikkelsen R (2016) IPW-5371 proves effective as a radiation countermeasure by mitigating radiation-induced late effects. Radiat Res 186:478-488. https://doi. org/10.1667/RR14403.2

163. Pala R, Anju VT, Dyavaiah M, Busi S, Nauli SM (2020) Nanoparticle-mediated drug delivery for the treatment of cardiovascular diseases. Int J Nanomedicine 15:3741-3769. https://doi. org/10.2147/IJN.S250872

164. Harries LW (2019) RNA biology provides new therapeutic targets for human disease. Front Genet. https://doi.org/10.3389/ fgene.2019.00205

165. Ha M, Kim VN (2014) Regulation of microRNA biogenesis. Nat Rev Mol Cell Biol 15:509-524. https://doi.org/10.1038/nrm3838

166. Hennessy EJ, Moore KJ (2013) Using microRNA as an alternative treatment for hyperlipidemia and cardiovascular disease: cardio-mirs in the pipeline. J Cardiovasc Pharmacol 62:247-254. https://doi.org/10.1097/FJC.0b013e31829d48bf

167. Sárközy M, Kahán Z, Csont T (2018) A myriad of roles of miR25 in health and disease. Oncotarget 9:21580-21612. https://doi. org/10.18632/oncotarget.24662

168. Hu Y, Xia W, Hou M (2018) Macrophage migration inhibitory factor serves a pivotal role in the regulation of radiation-induced cardiac senescencethrough rebalancing the microRNA-34a/sirtuin 1 signaling pathway. Int J Mol Med 42:2849-2858. https:// doi.org/10.3892/ijmm.2018.3838

169. Kura B, Yin C, Frimmel K, Krizak J, Okruhlicova L, Kukreja RC, Slezak J (2016) Changes of microRNA-1, -15b and -21 levels in irradiated rat hearts after treatment with potentially radioprotective drugs. Physiol Res 65(Suppl 1):S129-137. https://doi. org/10.33549/physiolres.933399

170. Esplugas R, Arenas M, Serra N, Bellés M, Bonet M, Gascón M, Vallvé J-C, Linares V (2019) Effect of radiotherapy on the expression Of cardiovascular disease-related miRNA-146a, -155, -221 and -222 in blood of women with breast cancer. PLoS ONE 14:e0217443. https://doi.org/10.1371/journal.pone.0217443

171. Dinh T-KT, Fendler W, Chałubińska-Fendler J, Acharya SS, O'Leary C, Deraska PV, D'Andrea AD, Chowdhury D, Kozono D (2016) Circulating miR-29a and miR-150 correlate with delivered dose during thoracic radiation therapy for non-small cell lung cancer. Radiat Oncol 11:61. https://doi.org/10.1186/s1301 4-016-0636-4 